\title{
Otimização do aproveitamento hídrico superficial na bacia hidrográfica do rio Araguari, Triângulo Mineiro
}

\section{Optimization of surface water use in the Araguari Riverwatershed, Triangulo Mineiro}

Data de entrada: 03/09/2017

Data de aprovação: 08/06/2018

Hélio Correia da Silva Jhunior ${ }^{1}$ | Marcio Ricardo Salla ${ }^{2 *} \mid$ Carlos Eugênio Pereira ${ }^{2}$ |

DOI: https://doi.org/10.36659/dae.2020.036

Amanda de Souza Nogueira ${ }^{2}$

\section{ORCID ID}

Jhunior HCS (D) https://orcid.org/0000-0003-3512-3943

Salla MR (D) https://orcid.org/0000-0003-2567-6173

Pereira CE (D) https://orcid.org/0000-0002-8250-715X

Nogueira AS (D) https://orcid.org/0000-0001-5800-6323

\section{Resumo}

Para a concessão de outorga em Minas Gerais, o IGAM adota como vazão de referência a $Q_{7,10}$ em base anual, aplicando-se o percentual outorgável máximo de 50\%. Com foco na otimização hídrica, o artigo teve como objetivo avaliar o impacto no potencial de usos da água ao se considerar novos critérios na estimativa da vazão de referência: a sazonalidade do regime de ocorrência de vazão e percentuais máximos outorgáveis acima de $50 \%$ da $Q_{7,10}$. O potencial desses novos critérios foi avaliado, tendo como prioridade garantir a vazão mínima residual ( $50 \%$ da $\left.Q_{7,10}\right)$ nos cursos de água. A área de estudo foi a bacia do rio Araguari, Minas Gerais. A substituição do critério anual pelo sazonal mostrou um aumento na vazão disponível para captação, principalmente no período chuvoso, sendo em média $47 \%$ superiores. A utilização de percentuais mais permissivos da $Q_{7,10}$ como critério de outorga frente ao atual teve, como principal resultado, a identificação de regiões onde, mesmo adotando $100 \%$ da $Q_{7,10}$ como vazão máxima outorgável, os volumes captados ultrapassam o máximo permitido. No que se refere às áreas críticas com conflitos entre demandas, foram estimados racionamentos significativos em períodos de estiagem, com um valor médio máximo mensal de 84,7\%. Nos reservatórios de Nova Ponte, Miranda, Capim Branco 1 e 2 do rio Araguari, o potencial ainda existente para captação se mostra favorável, com capacidade para abastecer cidades do porte de Uberlândia.

Palavras-chave: Otimização. OPTIGES. Vazão de referência.

\section{Abstract}

For the granting of a concession in Minas Gerais, the IGAM adopts a reference flow of $Q_{7,10}$ on an annual basis, applying the maximum grantable percentage of $50 \%$. The objective of this paper was to evaluate the impact on the potential of water uses when considering new criteria in the estimation of reference flow: the seasonality of the flow rate regime and maximum percentages that can be granted over $50 \%$ of $Q_{7,10^{\circ}}$. The potential of these new criteria was evaluated with priority being given to guaranteeing the minimum residual flow $\left(50 \%\right.$ of $\left.Q_{7,10}\right)$ in water courses. The study area was the Araguari river basin, Minas Gerais. The replacement of the annual criterion by the seasonal one showed an increase in the flow available for catchment, mainly in the rainy season, being on average $47 \%$ high-

\footnotetext{
${ }^{1}$ Escola de Engenharia de São Carlos - São Carlos - SP - Brasil.

${ }^{2}$ Faculdade de Engenharia Civil da Universidade Federal de Uberlândia - Uberlândia - MG - Brasil.

* Autor correspondente: sallamarcioricardoagmail.com.
} 
er. The use of more permissive percentages of $Q_{7,10}$ as a concession criterion compared to the current one, had, as main result, the identification of regions where, even adopting $100 \%$ of $Q_{7,10}$ as the maximum allowable flow, the volumes cap-tured exceed the maximum allowed. Concerning the critical areas with conflicts between demands, significant rationing was estimated in periods of drought, with a monthly maximum average value of $84.7 \%$. In the reservoirs of Nova Ponte, Miranda, Capim Branco 1 and 2 of the river Araguari, the potential existing for captation is favorable, with capacity to supply cities of the size of Uberlandia.

Keywords: Optimization. OPTIGES. Reference flow.

\section{INTRODUÇÃO}

As crises hídricas que afetam o Brasil nos últimos anos têm por origem a falta de um gerenciamento adequado, que conciliada a uma má distribuição espacial e temporal das precipitações, geram os problemas de disponibilidade de água. A recente crise hídrica no Brasil foi extrema, e a redução nos índices pluviométricos afetou diretamente a vazão dos rios, principalmente em regiões mais populosas (JARDIM, 2015). Segundo a Agência Nacional de Águas (ANA, 2015), a região Sudeste teve seu período crítico no ano de 2014, quando ocorreu uma seca com probabilidades de ocorrência inferiores a $1 \%$ (tempo de retorno superior a 100 anos).

A Lei Federal $n^{\circ}$ 9.433, de janeiro de 1997, prediz que a gestão dos recursos hídricos deve sempre proporcionar o uso múltiplo das águas. No Brasil, os principais usos consuntivos da água são divididos em irrigação, abastecimento humano, setor industrial e uso animal (SO-SINSKI, 2010). A irrigação é a maior parcela consumidora dos recursos hídricos na bacia hidrográfica do rio Araguari, com 55,48\% (CBH-ARAGUARI, 2016). $O$ crescimento significativo nas demandas de água para múltiplos usos resulta em impactos ambientais (quantitativos e qualitativos) e em conflitos pelo uso da água, afetando especialmente a manutenção de ecossistemas aquáticos naturais. Assim, a estimativa de uma vazão de referência adequada para os processos de outorga é indispensável.
As metodologias atuais utilizadas na estimativa de vazões de referência não foram desenvolvidas considerando aspectos principais de proteção ambiental, ficando em função de vazões baseadas em análises estatísticas (PINTO, RIBEIRO E SILVA, 2016; MEDEIROS, SOUZA E RIBEIRO, 2011; PRUSKI et al. 2014; VESTENA et al. 2012; TOMAZ, 2012). Segundo Longhi \& Formiga (2011), as metodologias usuais para estimativa dessas vazões de referência são baseadas em modelos estatísticos de distribuição probabilística, dentre eles: Gumbel, log-normal Pearson III, LogPearson III e Weibull.

Para a concessão de outorga no Estado de Minas Gerais, o Instituto Mineiro de Gestão das Águas (IGAM) adota como vazão de referência a fio de água a vazão mínima com 7 dias de duração e 10 anos de recorrência $\left(Q_{7,10}\right)$ em base anual, aplicando-se o percentual outorgável máximo de $50 \%$ dessa vazão para a maior parte do estado. Para sua estimativa, o IGAM segue a metodologia descrita no trabalho Deflúvios Superficiais no Estado de Minas Gerais, elaborado por Souza (1998). Esse critério de outorga está entre os mais rígidos do Brasil, podendo impedir a outorga de processos em situações onde há disponibilidade hídrica.

A aplicação de vazões de referência anuais limita o uso da água a um valor não correspondente na maior parte do ano. A sazonalidade do regime fluviométrico, se considerada na estimativa das vazões de referência, pode apresentar um aumento no volume outorgável, principalmente no 
período chuvoso (BOF, 2010; CORDEIRO \& MARQUES, 2012; COSTA, 2015; EUCLYDES, FERREIRA e FARIA FILHO, 2006; FLUMIGNAN et al. 2016; SILVA, MARQUES E LEMOS, 2011; OLIVEIRA, PRUSKI e NUNES, 2013; PRUSKI et al. 2014).

Para Andreu, Capilla e Sanchis (1996), a procura por soluções para os complexos problemas de planejamento e gerenciamento dos recursos hídricos se torna mais eficiente com a utilização de técnicas de otimização equacionadas por meio de algoritmos computacionais, em que se destaca o programa AQUATOOL (ÁLVAREZ, HERNÁNDEZ e SEGURA, 1986; ANDREU, CAPILLA e SANCHIS, 1996; COSTA, 2015; FERREIRA, 2014; PAREDES-ARQUIOLA, ÁLVAREZ e SOLERA, 2015; SALLA et al. 2013; SALLA et al. 2014a e 2014b), mais especificamente o módulo OPTIGES (CHÁVEZ-JIMÉNEZA \& GONZÁLEZ-ZEAS, 2015; HEINZ et. al. 2007; PELLICER-MARTÍNEZ \& MARTÍNEZ-PAZ, 2016; PA-REDES-ARQUIOLA et al. 2014a; SIMÕES \& OLIVEIRA, 2014).

Neste contexto, por meio do uso da ferramenta AQUATOOL, o presente artigo trabalha com a otimização do aproveitamento hídrico, fundamentado na hipótese de que a sazonalidade da disponibilidade e o uso de critérios menos restritivos constituem alternativas que podem pro-porcionar melhor uso da água na bacia do rio Araguari e, consequentemente, a redução de con-flitos atuais e potenciais nesta bacia. Foram avaliados o impacto na disponibilidade hídrica frente ao uso de vazões de referência baseadas em períodos sazonais (seco e chuvoso) e de percentuais acima de $50 \%$ da $Q_{7,10}$. Nas regiões críti- cas, onde os volumes demandados não permitem garantir a vazão mínima residual $\left(50 \%\right.$ da $\left.Q_{7,10}\right)$ em seus cursos de água, foram avaliadas possíveis soluções aos conflitos, com ponderação de níveis de prioridade e racionamentos no uso múltiplo da água. Além disso, buscou-se quantificar o potencial a ser outorgado nos principais reservatórios em cascata na bacia.

\section{METODOLOGIA}

\section{1 Área de estudo}

A bacia do rio Araguari está localizada na mesorregião do Triângulo Mineiro, situada a oeste do Estado de Minas Gerais, entre as coordenadas $18^{\circ} 20^{\prime}$ e $20^{\circ} 10^{\prime}$ de latitude Sul e $46^{\circ} 00^{\prime}$ e $48^{\circ} 50^{\prime}$ de longitude Oeste. Sua nascente encontra-se no Parque Nacional da Serra da Canastra, no município de São Roque de Minas e percorre 475 km até a sua foz no Rio Paranaíba, sendo um dos tributários do Rio Grande, que integra a Bacia Transnacional do Rio Paraná. Possui uma área de $22.091 \mathrm{~km}^{2}$, com população residente de aproximadamente 1,2 milhão de habitantes distribuída em 18 municípios. A bacia do rio Araguari foi dividida em dezoito sub-bacias, conforme ilustra a Fig. 1. O clima da região, segundo o CBH-Araguari (2016), é marcado por duas estações: uma seca, abrangendo os meses de maio a setembro, e outra úmida, com duração de outubro a abril. As precipitações mais elevadas ocorrem próximo aos municípios de Patrocínio e Tapira, chegando a valores anuais superiores a $1.600 \mathrm{~mm}$. 
Figura 1 - Sub-bacias que integram a bacia do rio Araguari

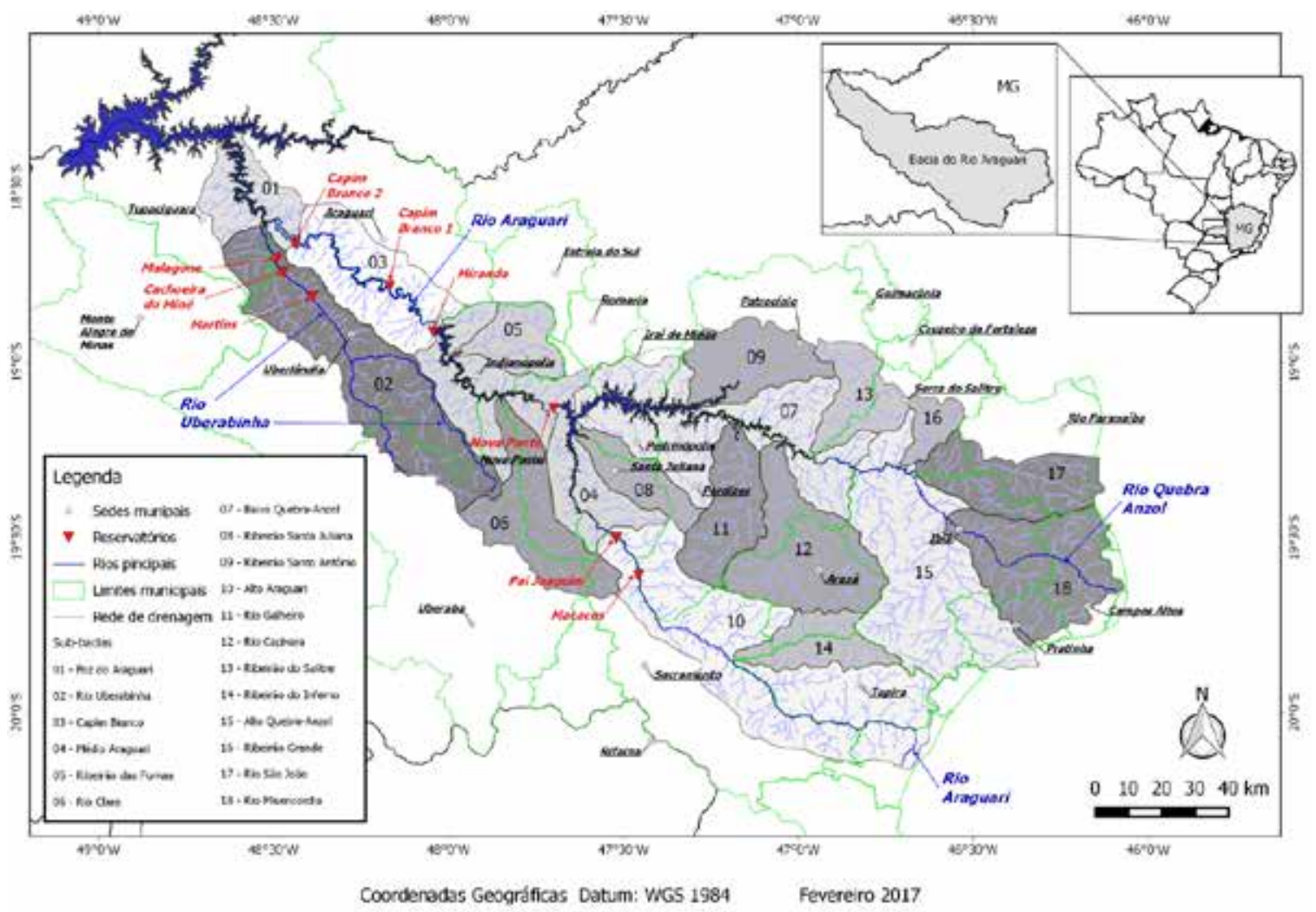

\subsection{Topologia - AQUATOOL}

A topologia construída na ferramenta AQUATOOL buscou representar toda a bacia do rio Araguari, considerando as 18 sub-bacias usuais e subdivisões destas, a fim de um maior detalhamento do comportamento hidráulico da bacia (vazões de entrada e saídas para demandas). Assim, a bacia do rio Araguari foi dividida em 183 trechos. A subdivisão em trechos foi realizada considerando os seguintes fatores:

- Número de outorgas no curso de água, ou seja, em uma região onde foi levantado um número significativo (acima de 1 com vazão total outorgada maior que $5 \mathrm{~L} / \mathrm{s}$ ) de outorgas houve um detalhamento maior, dividindo essas demandas para cada um dos tributários dos quais captam água. Regiões onde não houve outorgas levantadas ou com quantidade insignificante (outorgas pontuais com volume captado menor que $5 \mathrm{~L} / \mathrm{s}$ ) foram "simplificadas" em apenas um trecho;

- Os demais fatores foram aqueles usualmente empregados no processo de delimitação de uma bacia hidrográfica, como as curvas de nível do terreno e a hidrografia da região (VON SPERLING, 2007).

A estrutura da topologia é caracterizada por uma rede de fluxo fundamentada em elementos singulares e com funções distintas, sendo os principais aqueles referentes às entradas de água, às demandas e aos reservatórios. No que se refere às funções desses elementos que são necessárias às análises de otimização, vale ressaltar:

- Elementos do tipo aportação: correspondem às afluências de água para o sistema a partir da drenagem em uma área de contribuição (seja afluente de sub-bacia ou a própria sub-bacia). São definidas apenas por uma entrada pontual, 
representado séries mensais de vazões em hectômetros cúbicos.

- Elementos do tipo demanda: são definidos os valores mensais captados, além da possibilidade de fracionamento destes em porcentagens divididas em quatro níveis. Essa última opção foi utilizada em áreas onde a disponibilidade hídrica é insuficiente para atender a $100 \%$ das demandas. Por meio dessa função, denominada níveis de exigência, o modelo busca satisfazer primeiramente o primeiro nível de todas as demandas prioritárias, e em seguida, o primeiro nível das demandas com a prioridade seguinte, e assim por diante (AQUATOOL, 2016). Nesse elemento também são disponibilizados medidores de eficiência do processo de otimização, sendo utilizada neste estudo a garantia mensal. Seu objetivo é identificar falhas no fornecimento mensal de água para as demandas. Uma falha é contabilizada quando um determinado mês apresenta um déficit frente a uma porcentagem aceitável da demanda mensal estipulada pelo usuário. Assim, a garantia de eficiência da otimização pode ser medida pela Eq. 1.

$$
\mathrm{G}_{\mathrm{m}}=\left[1-\left(\frac{\mathrm{n}^{\circ} \text { de falhas }}{\mathrm{n}^{\circ} \text { total de meses }}\right)\right] \cdot 100
$$

- Elementos do tipo reservatórios: são definidas as características físicas dos reservatórios, dentre elas os volumes operacionais e a prioridade de reservação de cada reservatório, dado um sistema em cascata.

Os elementos secundários, tais como conduções, captações, nós ou conexões e retornos exercem funções de conectores da topologia e limitantes dos fluxos de entrada e saída de água ao longo da hidrografia estudada. Dentre eles, vale detalhar:

- Elemento do tipo captação: é o elemento que transfere água para uma determinada demanda e integra esta à rede de fluxo. Nestes são definidas as prioridades que cada uma das demandas tem sobre a outra, com valor mínimo igual a 1. Quanto menor a numeração recebida por determinada demanda, maior será sua prioridade no processo de otimização. Além disso, são especificados os coeficientes de retorno $\alpha$ e de consumo $\beta$, utilizados no cálculo da água que retorna para o sistema, definida pela Eq.2, e aquela consumida, conforme Eq.3). Para essa análise de otimização, a soma dos coeficientes $\alpha$ e $\beta$ foi definida como igual a 1, excluindo a possibilidade de infiltrações.

$$
\begin{aligned}
& R=\alpha \cdot S_{\text {sup }} \\
& R=\beta \cdot S_{\text {sup }}
\end{aligned}
$$

Nas quais: $\mathrm{S}_{\text {sup }}$ é o volume mensal captado pela demanda, em $\mathrm{hm}^{3}$.

Os valores de coeficientes de retorno foram adotados conforme ANA (2015), sendo, em média, 0,8 para abastecimento urbano, 0,8 para abastecimento rural, 0,8 para abastecimento industrial, 0,2 para irrigação e 0,2 para criação de animais. 0 ponto de retorno da água especificada na Eq. 2 é definido pela posição do elemento de retorno a ela relacionada.

- Elementos do tipo conduções: são definidas a capacidade máxima e a vazão mínima permitida nos cursos de água. Esse valor mínimo de escoamento é fundamental nas análises, pois é nesse item que é estabelecida a vazão mínima residual a ser respeitada, e também sua prioridade em relação aos demais objetivos no processo de otimização. Neste estudo, garantir a vazão mínima residual foi definida como a maior prioridade (número de prioridade 1).

A Fig. 2 traz apenas uma região de toda a topologia construída da bacia do rio Araguari, especificamente o alto curso do rio Quebra-Anzol. 
Figura 2 - Topologia da bacia do rio Araguari (alto curso do rio Quebra-Anzol)

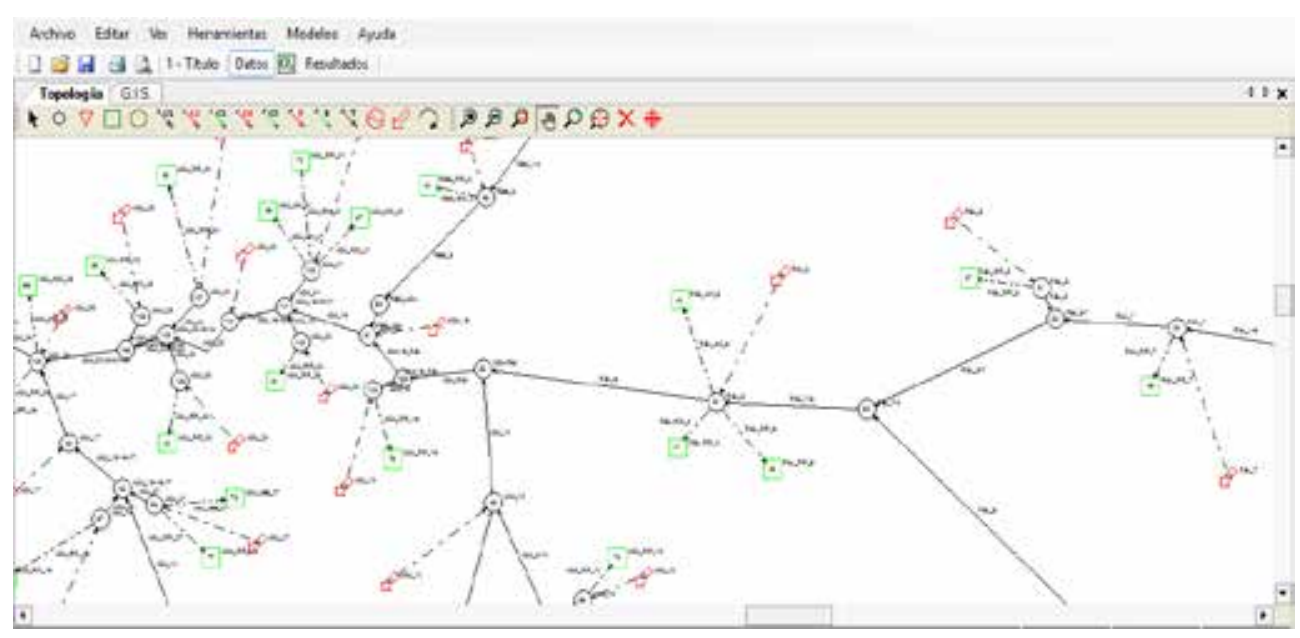

\subsection{Dados fluviométricos, pluviométricos e climatológicos}

Os dados hidrológicos de entrada requeridos pela topologia se limitam às séries históricas de vazões e aos valores mensais das demandas. 0 número de estações fluviométricas levantadas na bacia do rio Araguari é insuficiente, dado o tamanho da área de estudo. Logo, foi necessária a criação de séries sintéticas. Para essa estimativa foram organizados os dados fluviométricos e pluviométricos, obtidos junto ao Sistema de Informações Hidrológicas (HIDROWEB) da ANA, além de séries climatológicas referentes à evapotranspiração potencial, disponibilizadas pelo Instituto Nacional de Meteorologia (INMET). 0 período levantado foi aquele comum à maioria das séries de dados, sendo de 1975 a 2016.

A existência de lacunas temporais e espaciais nos dados coletados induziu à aplicação de metodologias para seu preenchimento. Dentre elas, regressões não lineares potenciais (aplicadas às séries evaporimétricas), além do método do inverso ponderado das distâncias (aplicado às séries pluviométricas). Essas metodologias são usuais e consagradas para esse tipo de estimativa (EU-
CLYDES, SOUZA e FERREIRA, 1999; GIRARDI et al. 2013; LADIM, 2000; SILVA, 2011; SOARES, 2000). 0 método de inverso ponderado das distâncias também foi utilizado na estimativa de séries pluviométricas e de evapotranspiração em regiões totalmente carentes de estações de monitoramento, sendo os pontos de interesse os centroides das sub-bacias e subdivisões consideradas.

\subsection{Modelo chuva-vazão HBV}

Por meio do modelo hidrológico chuva-vazão HBV, disponível na ferramenta Evaluación de los recursos Hidricos - EvalHID, foi possível a construção de séries sintéticas ao longo dos pontos de interesse da bacia, sendo esse programa consagrado nesse tipo de estimativa (COS-TA, 2015; MAS, 2013; PAREDES-ARQUUIOLA et al. 2014b; SALLA et al. 2015). A calibra-ção de seus parâmetros $\left(k_{0}, k_{1}, k_{2}, k_{\text {perc }} L_{\text {máx }}, P W P, F C\right.$ e $\left.\beta\right)$, necessária para adequar as simula-ções às características de cada sub-bacia, foi realizada via algoritmo evolutivo SCE-UA (Shuffled Complex Evolution method, University of Arizona), desen- 
volvido por Duan et al. (1992) apud Paredes-Arquiola et al. (2014b).

Os parâmetros calibrados também foram utilizados para as sub-bacias sem monitoramento hidrológico. Para isso foi utilizado o conceito de regiões hidrologicamente homogêneas (BARBOSA et al. 2005; EUCLYDES et al. 1999; HIDROTEC, 2016; TUCCI, 2005), onde o processo consistiu na repetição desses parâmetros ajustados para sub-bacias com distribuições percentuais de uso e ocupação do solo similares e contínuas entre elas (Fig. 3a). A Fig. 3b traz as estações fluviométricas utilizadas nas calibrações dos parâmetros do modelo HBV, além das sub-bacias nas quais foram aplicados os parâmetros calibrados. Nessa figura, o mapa foi construído considerando que as áreas delimitadas com a mesma cor possuem os mesmos parâmetros do modelo HBV, sendo aquelas com tonalidades claras aquelas em que foram adotados os parâmetros e aquelas com tonalidade escura aquelas em que foi possível realizar a calibração dos parâmetros e fornecê-los às demais.

Figura 3 - Bacia do rio Araguari: (a) Classificação do uso e ocupação do solo; (b) Estações fluviométricas utilizadas na calibração dos parâmetros do modelo HBV, com as respectivas sub-bacias onde estes foram aplicados

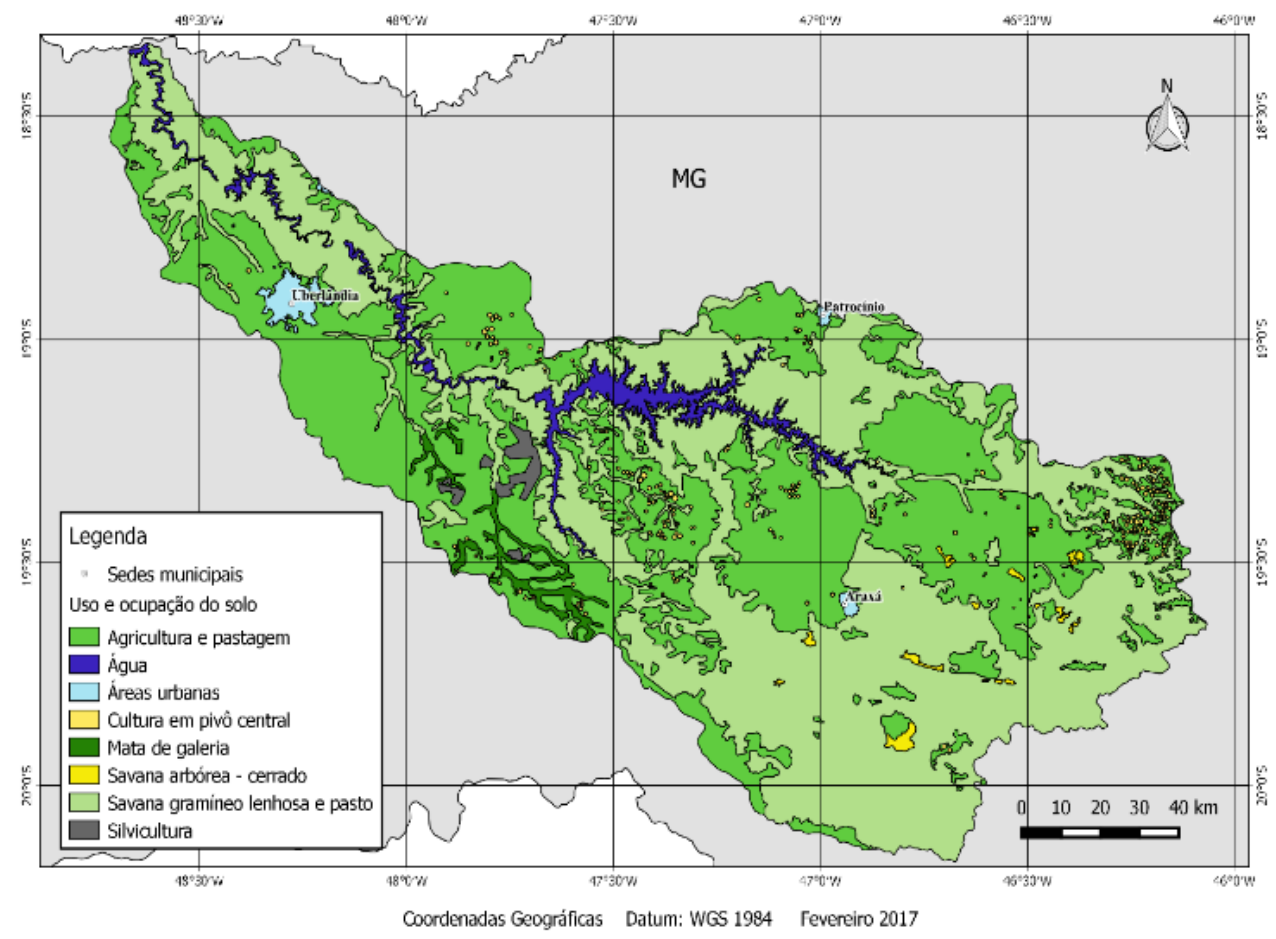

(a) 


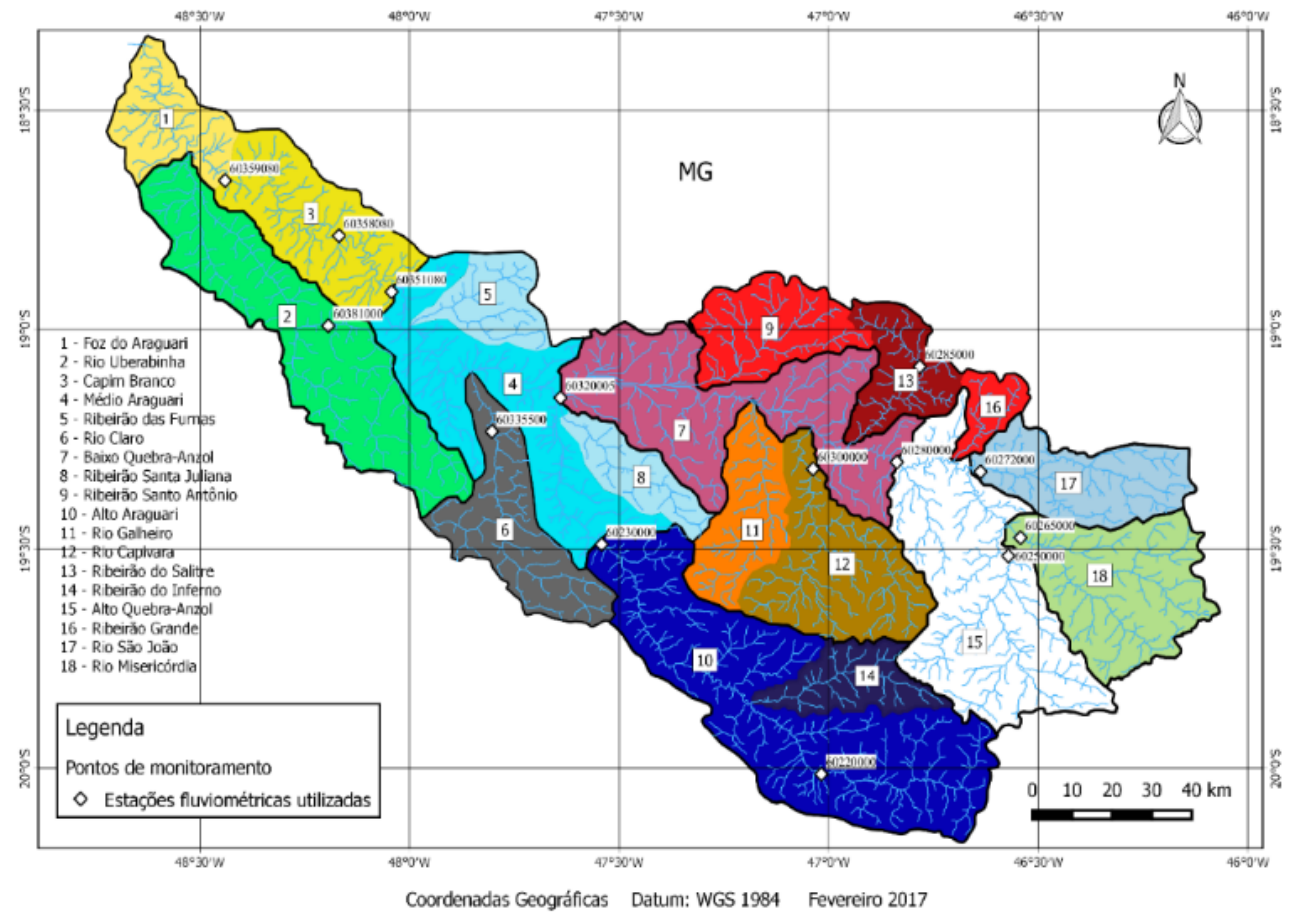

(b)

O processo de simulação, por meio da ferramenta EvalHid, foi realizado seguindo os seguintes procedimentos: primeiramente, para cada um dos 183 trechos considerados, foi delimitada a área de contribuição correspondente; em seguida foram localizados os centroides dessas áreas para cada um dos trechos; por meio do Método do Inverso Ponderado das Distâncias foram obtidas as séries de dados fluviométricos e de evapotranspiração nesses centroides; tendo, como dados de entrada, os valores de precipitação e evapotranspiração médios mensais e os parâmetros calibrados (na própria sub-bacia ou adotados), foram simuladas as séries sintéticas de vazões para cada um dos trechos. $O$ número de anos simulado, em função do período dos dados de entrada, foi de 40 anos (1975 até 2015).

\subsection{Demandas}

Para quantificar as demandas na bacia do rio Araguari foram consideradas as outorgas superficiais, a fio de água e em barramentos, obtidas junto ao
IGAM e à Secretaria de Estado de Meio Ambiente e Desenvolvimento Sustentável (SEMAD). Foram consultados os processos relativos às outorgas válidas e concedidas até junho de 2016. As análises das demandas foram feitas em base mensal e foi considerado o valor total de demanda, em cada trecho da hidrografia, obtido a partir do somatório dos valores outorgados nas seções a montante da confluência do trecho considerado com o trecho subsequente em cada mês. Estas foram divididas em quatro grupos: consumo humano, irrigação, indústria e dessedentação de animais, além das demandas não consuntivas para geração de energia elétrica. Apenas demandas superficiais foram consideradas, dada a dificuldade para quantificar a interdependência de rios e lagos com a água subterrânea (SILVA, 2007; SOPHOCLEOUS, 2002).

\subsection{Estimativa da $\mathrm{Q}_{7,10}$}

A definição da $Q_{7,10}$, aplicada como vazão mínima residual na topologia e como parte do critério máximo outorgável, sendo diferente para 
cada curso de água da hidrografia em estudo, foi realizada via equações fornecidas pelo Atlas Digital das Águas de Minas (2016). Suas equações são baseadas em distribuições de probabilidades (Weibull, log-normal III, log-Gumbel, Pearson tipo III e log- Pearson tipo III) e no conceito de regiões hidrologicamente homogêneas, onde por meio de modelos de regressão múltipla são determinadas as expressões matemáticas que relacionam as vazões mínimas na seção fluvial desejada com as variáveis área de drenagem, comprimento total dos cursos de água, densidade de drenagem, densidade hidrográfica e precipitação média. Estudos mais aprofundados e conhecimento das características da região em análise permitiram um equacionamento simplificado em função apenas da área de drenagem da bacia em questão (HIDROTEC, 2016). Com isso, a Eq. 4 foi utilizada na estimativa das vazões $Q_{7,10}$.

$\mathrm{Q}=\mathrm{a} \cdot \mathrm{A}^{\mathrm{b}}$

Na qual: $a$ e $b$ são parâmetros de ajuste, diferentes para cada curso de água e para os perí-odos considerados (sazonais e anual); $A$ é a área da bacia hidrográfica de interesse, em $\mathrm{km}^{2}$; $Q$ é a vazão mínima com 7 dias de duração e 10 anos de recorrência $\left(Q_{7,10}\right)$, em m³ $/$.

\subsection{Função objetivo}

A otimização da gestão de um sistema hídrico pelo módulo OPTIGES da ferramenta AQUATOOL, por um período de $\mathrm{N}$ anos, é realizada pela minimização da função objetivo descrita pela Eq. 5 . Esse equacionamento e os demais descritos neste item estão embutidos na programação da ferramenta utilizada. Termos referentes aos fluxos subterrâneos de água foram simplificados, uma vez que não fizeram parte deste estudo.
$\sum_{i=1}^{\mathrm{N}-12}\left[\sum_{i=1}^{n_{e}} T_{C}+\sum_{i=1}^{n_{d}} T_{D}\right]-\sum_{i=1}^{n_{e}} T_{E}$

Na qual: $n_{c}$ é o número de conduções do esquema; $n_{d}$ é o número de demandas; $n_{e}$ é o número de reservatórios; $T_{c}$ é a contribuição de cada condução, considerando vazões mínimas para a função objetivo; $T_{D}$ é a retirada de cada demanda para a função objetivo e $T_{E}$ é a contribuição de cada reservatório para a função objetivo.

O termo da função objetivo $T_{E}$ refere-se aos reservatórios, sendo calculado pelas Eq. 6 e 7.

$T_{E}=\sum_{i=1}^{\mathbb{N}-12-1} K_{E}-v_{i, t}+\tilde{\delta}_{i}-v_{i, N} \cdot 12$

$\delta_{i}=K_{E}+n_{e}-p_{i}^{e}$

Nas quais: $N$ é o horizonte de estudo, em anos; $K_{E}$ é um valor adotado (padrão $K_{E}=0$ ); $v_{i}$, $t$ é o volume armazenado no reservatório $i$ no mês $t ; \delta_{i}$ é o fator de ponderação atribuída ao volume armazenado no reservatório $i$ no final do período de otimização $N \cdot 12 ; n_{e}$ é o número de reservatórios existentes no regime; $p_{i}^{e}$ é a prioridade atribuída ao reservatório $i$.

$O$ termo da função objetivo $T_{C}$ se refere às conduções, calculado pelas Eq. 8 e 9.

$T_{C}=\sum_{j=1}^{n_{i}} \alpha_{i, j} \cdot d_{i, j, t}$

$\alpha_{i j j}=K_{a}-p_{i}^{e} \cdot K l-j \cdot K 2$

Nas quais: $n_{i}$ é o número de níveis no qual o fluxo mínimo da condução está dividido; $\alpha_{i}$, $j$ é o fator de ponderação atribuído ao déficit $d_{i^{\prime}} j{ }_{t}$, no mês t e nível de fluxo mínimo $j$ da condução $i ; K_{\alpha}$ é um 
valor adotado, sendo recomendado igual a 20000 (caracteriza situações onde as vazões mínimas nas conduções possuem prioridade absoluta sobre as demandas); $p_{i}^{c}$ é a prioridade atribuída a vazão mínima de uma condução $i$ em relação as demais; $j$ é o nível de fluxo mínimo para o qual se calcula $\alpha_{i}$; ; $K 1$ e $K 2$ são dois valores internos do modelo, sendo atribuídos a eles os valores $5 \mathrm{e}$ 200 , respectivamente.

O termo da função objetivo $T_{D}$ se refere às demandas, calculado pelas Eq. 10 a 12.

$$
\begin{aligned}
& T_{D}=\sum_{j=1}^{n_{i}^{s}} \beta_{i, j} \cdot d_{i, j, t}^{j}+\sum_{k=1}^{n_{i}} \gamma_{i, k} \cdot d_{i_{i} k_{a} t}^{t} \\
& \beta_{i j j}=K_{\beta}-j \cdot K 4 \\
& \eta_{i_{i} k}=-p_{i_{k} k}^{t} \cdot K 3
\end{aligned}
$$

Nas quais: $n_{i^{\prime}}$ é o número de níveis em que a demanda está dividida; $n_{t}$ é o número de captações que suprem a demanda $i ; \beta_{i}$, é o fator de ponderação atribuído ao déficit $d^{\prime}{ }^{\prime} j^{j}$, $t$ da demanda $i$ no mês $t$ para o nível de demanda $j ; \gamma_{i}$, é o fator de ponderação atribuído ao déficit d" ${ }_{i{ }^{\prime} k^{\prime}{ }_{t}}$ da demanda $i$ no mês $t$ por meio da captação $k$; $K_{\beta}$ é um valor adotado, sendo recomendado que seja igual a 10000; $p_{i{ }^{\prime} k}^{t}$ é a prioridade dada à captação $k$ da demanda $i$ no mês $t ; K 3$ e $K 4$ são valores internos do modelo e iguais a 5 e 200, respectivamente.

\subsection{Análises para otimização do aproveitamento hídrico}

\subsubsection{Primeira análise}

A primeira etapa avaliou as variações na quantidade de água disponível para outorga ao alterar o período base para o cálculo da $Q_{7,10}$ de anual para sazonal, sendo consideradas duas estações (chuvosa e seca). Foi avaliado também o impacto na disponibilidade ao se aumentar o percentual máximo outorgável, sendo analisados $60 \%, 70 \%$, $80 \%, 90 \%$ e $100 \%$ da $Q_{7,10}$, mantendo a base anual. Ambas as avaliações tiveram como prioridade a garantia da vazão mínima residual. A estimativa da disponibilidade hídrica foi feita considerando a quantidade de água retirada frente ao máximo permitido, conforme Eq.13.

$$
\%_{\text {retirada }}=\left(\frac{Q_{m}-Q_{j}}{\mathscr{\%} Q_{\%, 10}}\right)-100
$$

Na qual: $\%_{\text {retirada }}$ é a porcentagem captada frente ao máximo outorgável; $Q_{m}$ é a vazão a montante do trecho, em hm³/mês; $Q_{j}$ é a vazão a jusante do trecho, em hm³/mês; $\% Q_{7,10}$ é a vazão máxima outorgável do trecho para um determinado critério analisado, em $\mathrm{hm}^{3} / \mathrm{mês}$.

Os resultados foram avaliados em toda a hidrografia da bacia do rio Araguari, sendo classificados em trechos sem outorgas e onde a vazão outorgada frente ao máximo permitido da $\mathrm{Q}_{7,10}$ varia de: 0 a 1\%; 1 a 30\%; 30 a 50\%; 50 a $70 \%$; 70 a 100\%; 100 a 200\%; e acima de $200 \%$. O impacto da substituição dos critérios propostos também foi quantificado pelo método das diferenças relativas (DR\%), representado pela Eq.14.

$$
\mathrm{DR} \%=\left(\frac{\mathrm{Q}_{1}-\mathrm{Q}_{2}}{\mathrm{Q}_{2}}\right) \times 100
$$

Na qual: $D R \%$ é a diferença relativa entre a situação atual e a situação em análise, em \%; $Q$, representa a situação atual $\left(Q_{7,10}\right.$ anual), em hm³/mês; $Q_{2}$ a situação em comparação, ou com potencial de otimização, em $\mathrm{hm}^{3} / \mathrm{mês}$. 


\subsubsection{Segunda análise}

Foram avaliadas as áreas críticas na bacia, focando-se nas regiões com maior número de outorgas, onde a soma dos volumes captados ultrapassa o valor máximo permitido, e nos reservatórios de acumulação. No que se refere às áreas críticas, a primeira análise forneceu as regiões da bacia com outorgas acima de $50 \%$ da $Q_{7,10}$ anual. Assim, foi feita uma avaliação dos cortes necessários nessas demandas para que a vazão mínima residual $\left(50 \%\right.$ da $\left.Q_{7,10}\right)$ fosse garantida a jusante do ponto de outorga. Para a estimativa desses cortes, foram considerados diferentes níveis de prioridade entre as várias demandas na bacia. A Política Nacional de Recursos Hídricos, na Lei 9.433/97, institui que, em situações de escassez, o uso prioritário dos recursos hídricos é o consumo humano e a dessedentação de animais. A Política Estadual de Recursos Hídricos de Minas Gerais (PERH - MG), conforme Lei n 13.199/99, estabelece a prioridade para o abastecimento público e a manutenção dos ecossistemas. Já o Comitê da bacia do rio Araguari se limita a priorizar o consumo humano acima dos demais usos. A partir da falta de um consenso entre as legislações, foi adotada uma escala de prioridades entre as diferentes demandas da bacia do rio Araguari, sendo feitas algumas considerações. Primeiramente, o fato de o critério de outorga ser baseado na vazão ecológica define sua prioridade acima de qualquer demanda. No que se refere especificamente às vazões captadas para dessedentação animal, as outorgas levantadas (em média igual a $0,001 \mathrm{hm}^{3} / \mathrm{mês}-100$ vezes menor que as demais atividades) e a forma de captação (indiretamente por barramentos) resultaram na opção por agrupá-las junto às outras demandas "secundárias". Assim, os níveis de prioridade seguiram a seguinte ordem: $1^{\circ}$ - vazão ecológica ou de referência, $2^{\circ}$ - abastecimento público, $3^{\circ}$
- geração de energia, $4^{\circ}$ - irrigação, $5^{\circ}$ - consumo industrial, e $6^{\circ}$ - outros (dessedentação animal, lazer, lavagem e paisagismo). Além disso, foram atribuídas para cada demanda porcentagens mínimas a serem atendidas, divididas em 4 níveis de exigência, para cada um dos 5 tipos de demandas consideradas (AQUATOOL, 2016). Os resultados apresentados pela ferramenta indicam a partir de qual nível não foi mais possível atender à exigência determinada e, com isso, o percentual máximo possível de ser atendido para aquela demanda. Esse percentual foi o critério para a estimativa dos cortes necessários.

No que se refere aos reservatórios ( $\mathrm{CH}$ Nova ponte, $\mathrm{CH}$ Miranda, $\mathrm{CH}$ s Capim branco 1 e 2, em cascata), a primeira análise forneceu, para o critério atual ( $50 \%$ da $\mathrm{Q}_{7,10}$ anual), a situação destes quanto às demandas atendidas (junto à barragem e trechos a montante), a limitação da vazão mínima a jusante, e as cotas mínimas e volumes mínimos turbinados para a operação das respectivas hidroelétricas. Para os reservatórios onde as exigências citadas anteriormente foram respeitadas, realizou-se a estimativa de vazões mensais máximas que ainda poderiam ser captadas, respeitando-se, obviamente, as mesmas exigências.

\subsubsection{Períodos críticos}

Os resultados das análises foram apresentados apenas nos períodos críticos. Para isso, foi considerada a variação do regime pluviométrico ao longo do ano, sendo adotados dois períodos característicos, o chuvoso e o de estiagem. Em cada um deles foi estimado o mês mais crítico, tendo como critério o volume outorgado em determinado mês. Assim, o mês com o maior volume outorgado no período de estiagem foi Agosto, e para o período chuvoso, Outubro. 


\section{RESULTADOS}

\subsection{Análises para otimização do} aproveitamento hídrico - Primeira análise

\subsubsection{Impacto da substituição da $Q_{7,10}$ anual pelas $Q_{7,10}$ sazonais}

O impacto da substituição do período anual pelos sazonais, considerados os meses de Agosto (seco) e Outubro (chuvoso), é evidenciado na Fig. 4, onde são apresentadas as curvas que relacionam as diferenças relativas (DR\%) entre as $Q_{7,10}$ sazonais e a $Q_{7,10}$ anual com a frequência que ocorrem na hidrografia analisada. A série " $Q_{7,10}$ cheia" refere-se à $\mathrm{DR} \%$ entre as vazões mínimas calculadas para períodos anuais frente aquelas, considerando o período sazonal de cheias, e a série " $Q_{7,10}$ seca" a DR\% entre as $Q_{7,10}$ anuais e aquelas referentes aos meses mais secos.

Figura 4 - Diferenças relativas (DR\%) entre os valores de $Q_{7,10}$ baseados no período anual e sazonais (estações chuvosa e seca), com a frequência de ocorrência nos trechos da hidrografia na bacia do rio Araguari

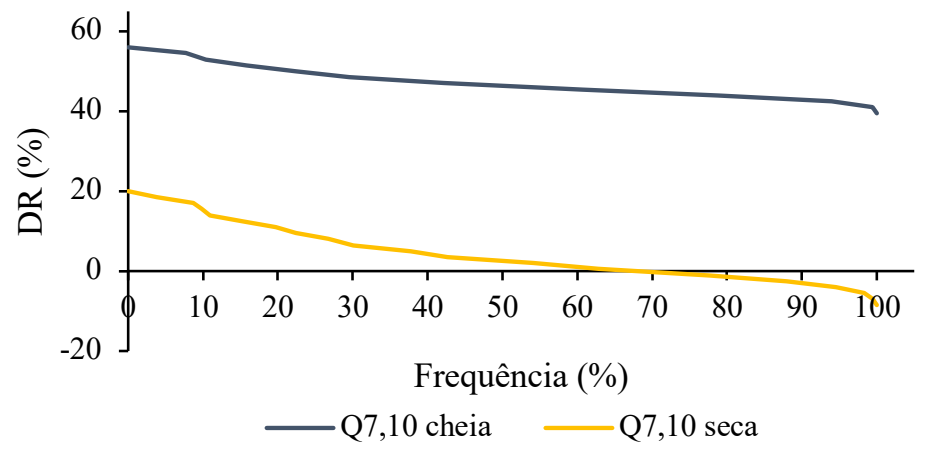

Para a série " $\mathrm{Q}_{7,10}$ cheia" observa-se uma tendência progressiva de queda das diferenças entre os métodos comparados conforme o número de trechos analisados aumenta, com uma amplitude próxima a $15 \%$. Além disso, seus valores são mantidos positivos em $100 \%$ da hidrografia, sendo sempre superiores a $40 \%$ e chegando a um máximo em torno de 55\%, com uma média de 47\%. Assim, a utilização da base de cálculo sazonal neste período revela um grande potencial de aumento no aproveitamento hídrico, visando atender e até mesmo ampliar o número de outorgas atuais. Entretanto, cerca de $50 \%$ do volume captado anualmente é destinado à irrigação, que apresenta, nesse período, uma diminuição significativa (14\% aproximadamente). Assim, uma opção para o aumento nos volumes outorgados seria reservar para uma posterior utilização durante a estação seca.

A situação varia para os demais meses do ano. A série " $Q_{7,10}$ seca" também apresenta uma queda progressiva das $\mathrm{DR} \%$, sendo aproximadamente $70 \%$ dos trechos compostos por valores positivos, chegando a $20 \%$ e não apresenta queda acentuada. Isso demonstra o potencial a ser explorado nas regiões correspondentes a essa parcela, que representa uma garantia do atendimento e possível ampliação do volume atualmente outorgado.

Acima desse valor na escala de frequência há um ponto de inversão, mostrando que em quase $30 \%$ dos trechos a substituição da $Q_{7,10}$ anual pela $Q_{7,10}$ seca não seria justificável, no que se refere ao aumento da disponibilidade de volume a 
ser outorgado. Além disso, essa parcela aponta para possíveis valores de $Q_{7,10}$ superestimados pelo critério atual ( $50 \%$ da $\mathrm{Q}_{7,10}$ anual), colocando em risco os ecossistemas da região. Esse fato, porém, justificaria a aplicação do critério sazonal (meses de abril a setembro) visando garantir e prevenir qualquer violação à vazão mínima ecológica, o que levaria, consequentemente, à reduções nos volumes atualmente outorgados nas regiões correspondentes a essa parcela. $O$ contrabalanceamento com o aumento dos volumes outorgáveis nos meses de outubro a abril poderia ser uma alternativa para essa redução hídrica disponível à captação.

Os mapas de disponibilidade, apresentados na Fig. 5 para as situações comparadas, tiveram como objetivo propiciar uma visão geral de suas condições e a identificação das regiões críticas e promissoras da bacia antes e após a aplicação do critério sazonal. Considerando o critério de outorga atual ( $50 \%$ da $\mathrm{Q}_{7,10}$ anual), a situação na bacia é, em grande parte, confortável. As Fig. 5a e $5 b$ mostram, respectivamente, a disponibilidade hídrica para os meses críticos das estações chuvosa e seca. As áreas com outorgas que captam até $50 \%$ do permitido ocupam grande parte da área da bacia, cerca de aproximadamente $60 \%$ para ambos os períodos do ano. Essas regiões são aquelas próximas aos rios principais, rio Araguari e Quebra-Anzol, já que estes drenam o maior volume da bacia. Em torno de $10 \%$ da hidrografia permanece com captações entre $50 \%$ e o máximo outorgável. Essas regiões (70\% da área da bacia) são as mais promissoras para a aplicação do critério sazonal, visando ampliar o potencial outorgável sem ameaçar a vazão mínima residual.

Nas regiões de cabeceiras ocorrem as situações mais críticas, onde chegam a mais de $200 \%$ do permitido. Cerca de $14 \%$ da área da bacia apresenta cursos de água com captações acima de $50 \%$ da $Q_{7,10}$ nos meses chuvosos. Essa porcen- tagem sobe para $16 \%$ no período de estiagem. As sub-bacias mais afetadas são: Ribeirão Santo Antônio, Ribeirão Santa Juliana e Ribeirão Furnas onde, respectivamente, $50 \%$, $60 \%$ e $84 \%$ das suas áreas captam volumes acima do determinado pelo IGAM. Nessas regiões, uma revisão dos volumes atualmente outorgados é necessária e fundamental para a adequação ambiental.

As Fig. 5 c e $5 d$ se referem à disponibilidade hídrica para os meses críticos das estações chuvosa e seca, considerando a $Q_{7,10}$ baseada nos seus respectivos períodos sazonais para os meses com maior retirada. Há um aumento nas regiões em acordo com a legislação, onde pelo menos $73 \%$ da bacia apresenta outorgas que somam volumes menores do que $50 \%$ da $Q_{7,10}$ nos meses de outubro a março. Para os demais meses do ano, essa parcela diminui, mas permanece sendo a maioria, chegando a $68 \%$. No que diz respeito à disponibilidade e ao potencial de aproveitamento hídrico dos trechos considerados, os resultados mostram que cerca de $90 \%$ deles não chegam a captar metade do máximo permitido, um aumento de aproximadamente $20 \%$ em relação ao critério atual (50\% da Q7,10 anual).

Nos meses de outubro a março, a transição mais significativa foi referente à situação em que o volume retirado está entre 30 e $50 \%$, sendo um crescimento de $58 \%$ nos cursos nela inseridos. Também vale citar que aproximadamente 15\% da hidrografia da bacia apresentava um grande potencial de exploração do uso da água, ficando abaixo de $1 \%$ do permitido. Com a mudança de critério, essa porcentagem passou a ser de $19 \%$, representando um aumento de $21 \%$. Para as situações onde as demandas superam o dobro do permitido, a substituição da $Q_{7,10}$ anual pela $Q_{7,10}$ cheia gerou resultados significativos. $O$ número de trechos nessa situação apresentou uma diminuição de $42 \%$. Os trechos com outorgas entre $100 \%$ e $200 \%$ apresentaram uma diminuição de aproximadamente $36 \%$. Esses percentuais 
identificam quão promissora é a consideração da sazonalidade visando a ampliar o número e o volume das outorgas, excluindo apenas aquelas regiões onde, mesmo aumentando a vazão de referência, os pontos de captação atuais ultrapassam o valor máximo. Nestas, novamente, uma revisão das demandas deferidas é fundamental para a manutenção dos volumes mínimos.

Figura 5 - Porcentagem de volume captado frente ao máximo permitido em cada trecho da hidrografia na bacia do rio Araguari, para cada um dos seguintes critérios: (a) $50 \%$ da $\mathrm{Q}_{7,10}$ anual período chuvoso; (b) $50 \%$ da $\mathrm{Q}_{7,10}$ anual período seco; (c) $50 \%$ da $\mathrm{Q}_{7,10}$ sazonal período chuvoso; (d) $50 \%$ da $\mathrm{Q}_{7,10}$ sazonal período seco;

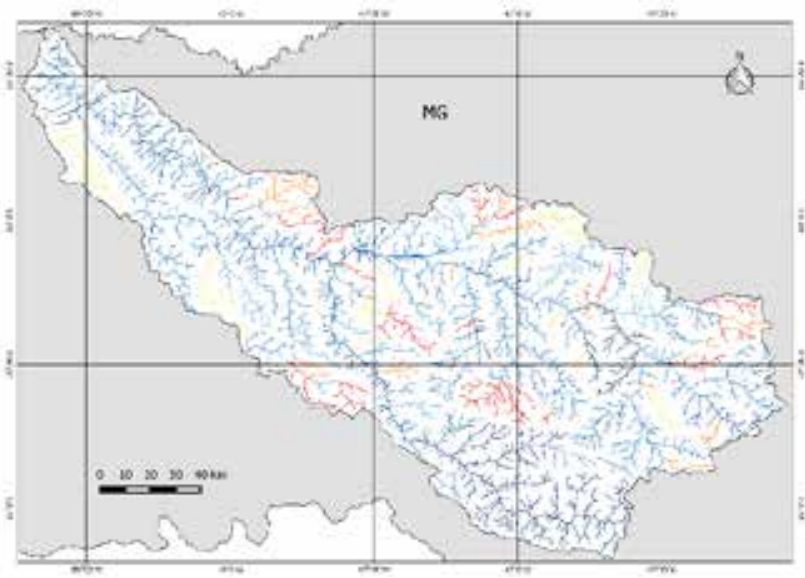

(a)

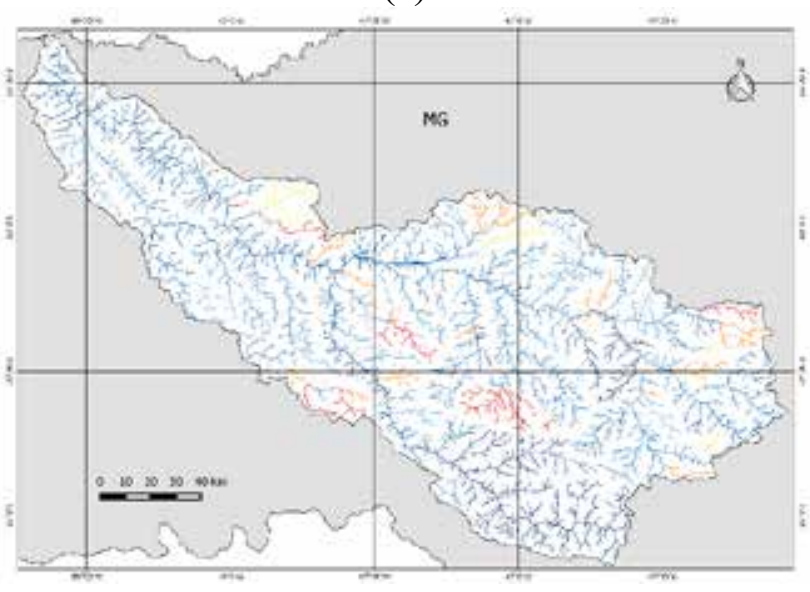

(c)

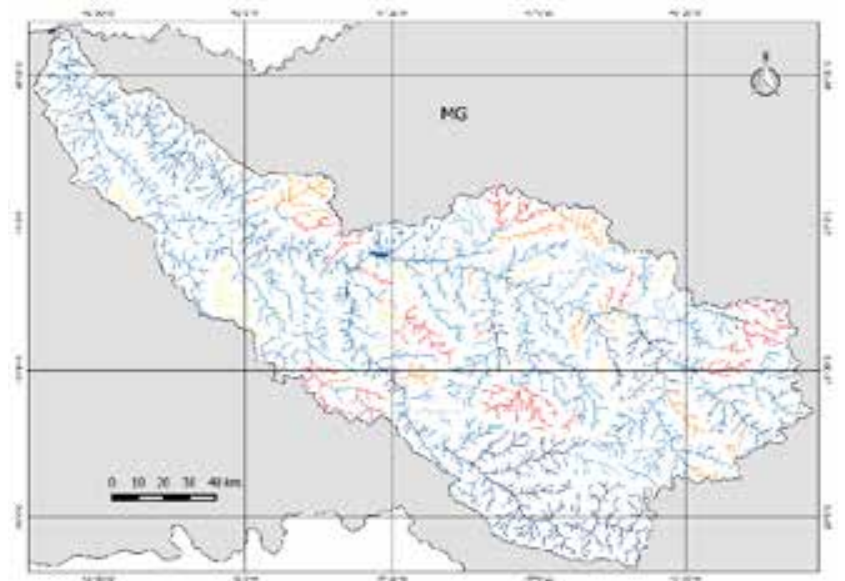

(b)

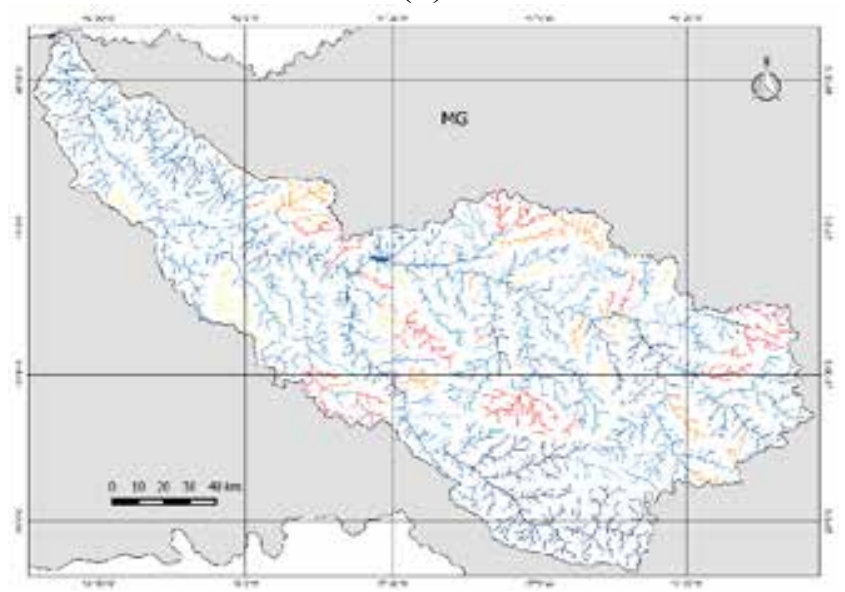

(d)

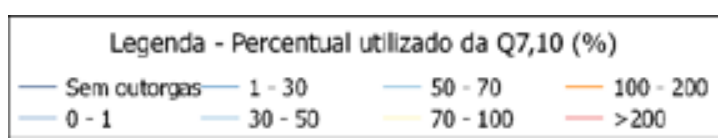


A situação não é tão promissora para a estação de estiagem. Não houve impacto significativo na disponibilidade hídrica após a mudança de critério de anual para sazonal, conforme se observa pelas semelhanças entre a escala de cores da hidrografia nas Fig. 5 b e $5 d$, segundo a classificação proposta (legenda - Fig. 5). Essa inalterabilidade pode estar relacionada a dois fatos. Primeiramente, conforme a série " $Q_{7,10}$ seca" da Fig. 4, nem todos os trechos apresentam um aumento no potencial do volume outorgável, sugerindo que $30 \%$ dos cursos (representados pelo intervalo de $70 \%$ a $100 \%$ na abscissa - Fig. 4) podem estar com a vazão de referência subestimada. Em segundo lugar, esses trechos com vazões subestimadas apresentam uma amplitude baixa (em torno de 10\%), o que caracteriza valores de vazões próximas obtidas pelos critérios anual e sazonal seco. Da mesma forma, parte dos $70 \%$ dos trechos onde a vazão sazonal seca é maior que a anual (representados pelo intervalo de $20 \%$ a $70 \%$ na abscissa - Fig. 4) também apresenta uma amplitude baixa (igual a 10\%).

Ainda assim, conforme citado anteriormente na descrição da Fig. 5b, a identificação das regiões mais promissoras à ampliação do volume outorgado ( $70 \%$ da área da bacia) e daquelas críticas à manutenção da vazão residual (16\%) possibilitam, conforme cada situação, a aplicação do critério sazonal.

\subsubsection{Impacto da mudança do percentual máximo outorgável da $Q_{7,10}$ anual na disponibilidade}

O impacto das alterações na disponibilidade hídrica ao longo da bacia em função dos per-centuais de $60 \%, 70 \%, 80 \%, 90 \%$ e $100 \%$ da $Q_{7,10}$ com base anual são apresentados de forma resumida na Tabela 1, onde são mostradas as porcentagens da área da bacia do rio Araguari, onde o volume captado é menor do que o limite permitido, e aquelas onde esse limite é ultrapassado, considerando cada um dos critérios analisados. O fato de aumentar a porcentagem outorgável da $Q_{7,10}$ leva à previsão de certa diminuição dos pontos críticos e ao aumento da disponibilidade hídrica de uma forma geral na bacia.

Tabela 1- Porcentagens da área na bacia do rio Araguari com volumes captados abaixo e acima do valor máximo permitido, segundo cada um dos critérios analisados, para a divisão sazonal em cheia e seca

\begin{tabular}{|c|c|c|c|c|c|c|c|c|c|c|c|c|}
\hline \multirow{2}{*}{$\begin{array}{c}\text { Máx. } \\
\text { permitido } \\
\text { Estações }\end{array}$} & \multicolumn{2}{|c|}{$50 \%$ da $Q_{7,10}$} & \multicolumn{2}{|c|}{$60 \%$ da $Q_{7,10}$} & \multicolumn{2}{|c|}{$70 \%$ da $\mathbf{Q}_{7,10}$} & \multicolumn{2}{|c|}{$80 \%$ da $Q_{7,10}$} & \multicolumn{2}{|c|}{$90 \%$ da $Q_{7,10}$} & \multicolumn{2}{|c|}{$10 \%$ da $Q_{7,10}$} \\
\hline & Seca & Chuva & Seca & Chuva & Seca & Chuva & Seca & Chuva & Seca & Chuva & Seca & Chuva \\
\hline De 0 a $100 \%$ & $85,3 \%$ & $83,4 \%$ & $86,8 \%$ & $85,6 \%$ & $88,5 \%$ & $87,5 \%$ & $88,7 \%$ & $88,0 \%$ & $89,6 \%$ & $88,8 \%$ & $90,6 \%$ & $89,5 \%$ \\
\hline$>100 \%$ & $14,6 \%$ & $16,5 \%$ & $13,2 \%$ & $14,4 \%$ & $11,5 \%$ & $12,6 \%$ & $11,3 \%$ & $12,0 \%$ & $10,4 \%$ & $11,2 \%$ & $9,4 \%$ & $10,5 \%$ \\
\hline
\end{tabular}

As Fig. $6 \mathrm{a}$ e $6 \mathrm{~b}$ demonstram as porcentagens da área da bacia referentes a cada um dos intervalos da classificação de cores proposta, respectivamente, para o período chuvoso e o seco. As distribuições para ambos os períodos apresentam com- portamento similar, com $40 \%$ em média da área hidrográfica da bacia com volumes outorgados entre $1 \%$ e $30 \%$, conforme os mapas apresentados, evidenciando a situação da disponibilidade hídrica como satisfatória em grande parte da hidrografia. 
Figura 6 - Porcentagem da área da bacia referente a cada intervalo da classificação nos períodos: (a) chuvoso; (b) seco

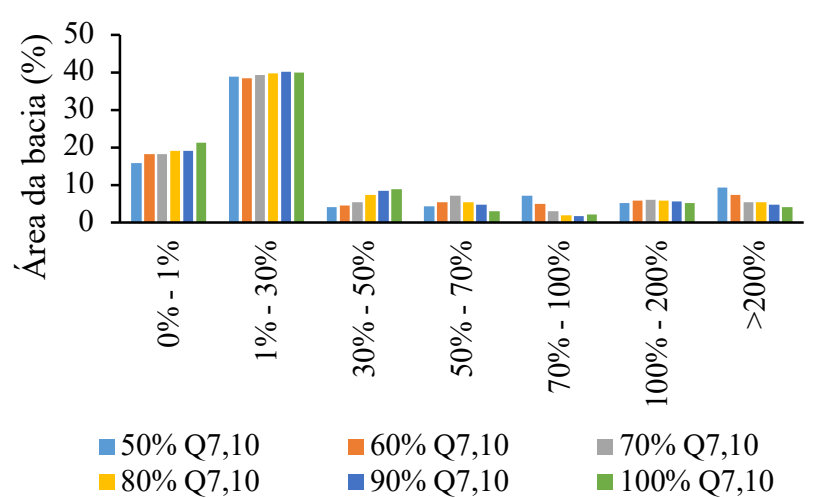

$80 \% \mathrm{Q} 7,10$

$100 \% \mathrm{Q} 7,10$

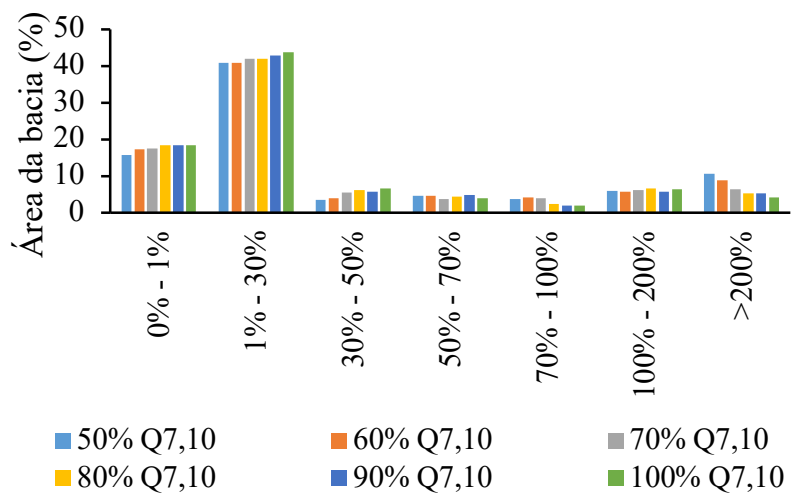

Ainda na Fig. 6, como previsto, os 3 primeiros intervalos de classificação $(0 \%$ a $1 \%, 1 \%$ a $30 \%$ e $30 \%$ a $50 \%$ ) incorporam uma quantidade maior de área ao se alterar o critério vigente, caracterizado pelo crescimento no tamanho das respectivas colunas nos gráficos. A adoção das porcentagens de $Q_{7,10}$ leva a um aumento de $4,5 \%$ em média na área da bacia para os três primeiros intervalos de classificação. Os demais intervalos de classificação apresentam comportamentos irregulares por conta da transição no enquadramento dos trechos que fariam parte do intervalo do "nível" acima. Entretanto, a tendência geral é de diminuição das áreas compreendidas entre as parcelas de $50 \%$ a $70 \%$ e entre $70 \%$ e $100 \%$, justificando o aumento nos intervalos inferiores

O resultado mais expressivo dessa análise se refere às áreas onde o volume outorgado ultrapassa o máximo permitido. Na Fig. 7 são apresentados os percentuais dos trechos acima do volume máximo permitido de captação (100\% - 200\% e > 200\%), para cada um dos cenários nos dois períodos sazonais. Para a situação atual, nos meses críticos de cheia, $22 \%$ dos trechos analisados apresentam essa inadequação, reduzindo para $12 \%$ para outorgas máximas iguais a $Q_{7,10}$.

Figura 7 - Porcentagem dos trechos da topologia da bacia acima da volume máximo permitido de captação para cada cenário

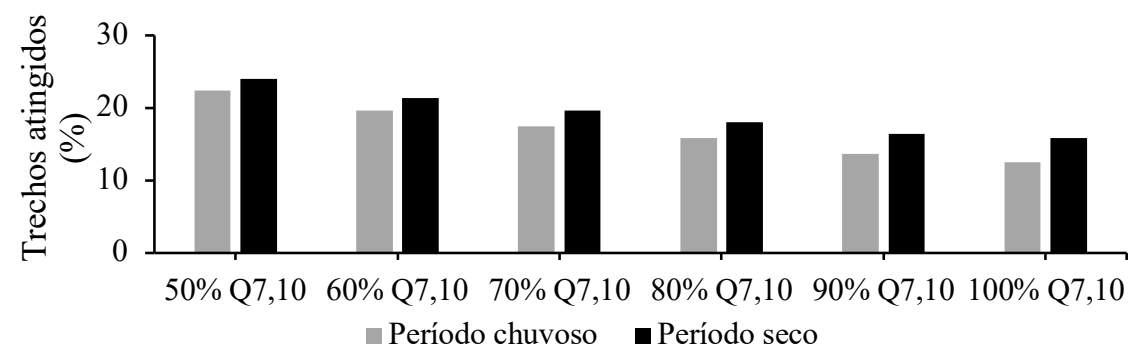


Em média, há uma redução de aproximadamente $9,5 \%$ na mudança de uma porcentagem da $Q_{7,10}$ para outra. As regiões acima do valor máximo outorgável continuam sendo aquelas localizadas nas cabeceiras, onde vale destacar as sub-bacias do Ribeirão Santo Antônio, Ribeirão Santa Juliana e Ribeirão Furnas.

Assim, a relevância da série de resultados apresentados está no fato de que, mesmo após aumentar a máxima porcentagem da $\mathrm{Q}_{7,10}$ outorgável, são encontradas regiões (aproximadamente $12 \%$ da área da bacia) onde as demandas permanecem acima do valor máximo permitido. Isso indica, novamente, a necessidade de análises aprofundadas acerca do deferimento de outorgas nesses trechos e o real risco à manutenção das vazões mínimas residuais.

\subsection{Análises para otimização do aproveitamento hídrico - Segunda análise}

\subsection{1 Áreas críticas}

Os resultados referentes às áreas críticas (regiões que demandam volumes que não garantem a vazão mínima residual nos rios de $50 \%$ da $Q_{7,10}$ ) são apresentados na Tabela 2 e na Fig. 8. Essas regiões críticas estão inseridas nas subbacias dos rios Uberabinha (regiões 1 e 2), São João (região 3), Capivara (regiões 4, 5 e 6), Santo Antônio (regiões 7 e 8), Furnas (região 9), Médio Araguari (região 10) e Alto Quebra Anzol (regiões 11, 12 e 13).

De uma forma geral, os resultados mostraram eventos máximos alarmantes, mas pontuais, justificados por probabilidades extremas de ocorrência. Quando considerada sua ocorrência média ao longo dos 40 anos simulados, os déficits encontrados são significativamente menores (82\%, em média). Entretanto, ambas as situações apontam que, para outorgas excessivas sem os racionamentos estimados, a garantia da vazão mínima seria comprometida, como apresentado a seguir. Essa análise aponta, novamente, para a necessidade de revisão dos valores atualmente outorgados nestas regiões.

A sub-bacia do Uberabinha foi aquela que apresentou os maiores déficits e afetou demandas com maior importância, o abastecimento público da cidade de Uberlândia. No reservatório de Sucupira (região 2 - Fig. 8), foi estimado que períodos de estiagem afetariam 2,7\% dos meses, quando não seria possível atender totalmente à demanda de abastecimento sem comprometer a vazão mínima residual ( $50 \%$ da $Q_{7,10}$ ). Essa parcela está relacionada à garantia mensal (Eq. 1) encontrada de 97,3\%. Assim, neste período seria necessário um corte de até $50 \%$ na vazão captada, cerca de 4,8 $\mathrm{hm}^{3}$ mensais. Essa foi a porcentagem máxima encontrada nos níveis de exigência para que não ocorresse nenhum mês com déficit frente ao exigido. 0 valor médio mensal de déficit de $0,12 \mathrm{hm}^{3}$ aponta que a porcentagem de corte de $50 \%$ seria para um mês extremo, sendo o corte médio na vazão outorgada para os períodos críticos bem abaixo desse valor, em torno de 1,3\% (porcentagem da demanda). Apesar da estimativa de cortes máximos significati-vos (50\%), a quantidade de meses em déficit foi pequena frente ao período analisado $(2,7 \%$ dos meses, em um período de 40 anos), o que mostra a necessidade de eventos raros de estiagem para que possíveis ações como essas fossem tomadas. Esses eventos seriam caracterizados por vazões médias mensais próximas a $Q_{7,10}$, sendo em torno de $5,70 \mathrm{hm}^{3} / \mathrm{mês}$ no rio Uberabinha a jusante do reservatório de Sucupira.

A interpretação dos demais resultados apresentados na Tabela 2 segue o mesmo processo citado anteriormente. Naquelas em que o número de meses afetados se julgou significativo (próximos a 5\%), foi apresentada a correlação entre o déficit atingido e os meses de ocorrência (Fig. 9). 
Tabela 2 - Regiões com áreas críticas

\begin{tabular}{|c|c|c|c|c|c|c|c|c|}
\hline $\begin{array}{l}\text { Região } \\
\text { afetada }\end{array}$ & $\begin{array}{c}\% \\
\text { meses em } \\
\text { déficit }^{1}\end{array}$ & $\begin{array}{l}\text { Atividade em } \\
\text { conflito }\end{array}$ & $\begin{array}{c}\text { Volume } \\
\text { outorgado } \\
\text { (hm³/mês) }\end{array}$ & $\begin{array}{l}50 \% \text { Q7 } \\
\left(\mathrm{hm}^{3} / \mathrm{mế}^{10}\right)\end{array}$ & $\begin{array}{l}\text { Máx. déficit } \\
\left(\mathrm{hm}^{3}\right)^{1}\end{array}$ & $\begin{array}{c}\text { Máx. corte } \\
(\%)^{1}\end{array}$ & $\begin{array}{l}\text { Déficit } \\
\text { médio } \\
\left(\mathrm{hm}^{3}\right)^{1}\end{array}$ & $\begin{array}{c}\text { Corte médio } \\
(\%)^{1}\end{array}$ \\
\hline Região 1 & $2,5 \%$ & Abast. público & 5,18 & 1,40 & 3,90 & $48 \%$ & 0,06 & $1,2 \%$ \\
\hline Região 2 & $2,7 \%$ & Abast. público & 9,59 & 2,85 & 7,50 & $50 \%$ & 0,12 & $1,3 \%$ \\
\hline Região 3 & $2,7 \%$ & Irrigação & 0,97 & 0,56 & 1,00 & $62 \%$ & 0,11 & $1,2 \%$ \\
\hline Região 4 & $7,9 \%$ & Cons. industrial & 4,75 & 0,86 & 2,60 & $55 \%$ & 0,12 & $2,6 \%$ \\
\hline Região 5 & $10,0 \%$ & Cons. industrial & 4,98 & 0,65 & 2,60 & $55 \%$ & 0,12 & $2,6 \%$ \\
\hline Região 6 & $53,0 \%$ & Cons. industrial & 1,70 & 0,16 & 1,70 & $99 \%$ & 0,785 & $46,8 \%$ \\
\hline Região 7 & $4,2 \%$ & Irrigação & 0,67 & 0,26 & 0,60 & $83 \%$ & 0,02 & $2,4 \%$ \\
\hline Região 8 & $2,1 \%$ & Irrigação & 0,42 & 0,26 & 0,40 & $83 \%$ & 0,01 & $2,0 \%$ \\
\hline Região 9 & $7,1 \%$ & Irrigação & 3,26 & 0,41 & 2,10 & $71 \%$ & 0,06 & $2,0 \%$ \\
\hline Região 9 & $7,3 \%$ & Outros $^{2}$ & 0,60 & 0,41 & 0,03 & $99 \%$ & 0,01 & $1,6 \%$ \\
\hline Região 10 & $5,0 \%$ & Irrigação & 0,97 & 0,14 & 0,60 & $65 \%$ & 0,02 & $2,0 \%$ \\
\hline Região 11 & $37,3 \%$ & Irrigação & 0,50 & 0,29 & 0,50 & $99 \%$ & 0,33 & $70,0 \%$ \\
\hline Região 12 & $4,4 \%$ & Irrigação & 0,21 & 0,86 & 0,10 & $35 \%$ & 0,10 & $4,8 \%$ \\
\hline Região 13 & $85,4 \%$ & Irrigação & 0,06 & 0,10 & 0,06 & $88 \%$ & 0,05 & $84,7 \%$ \\
\hline
\end{tabular}

${ }^{1}$ período analisado de 40 anos

${ }^{2}$ dessedentação animal, lazer, lavagem e paisagismo

Figura 8 - Regiões críticas na bacia do rio Araguari, com a localização e o tipo das outorgas

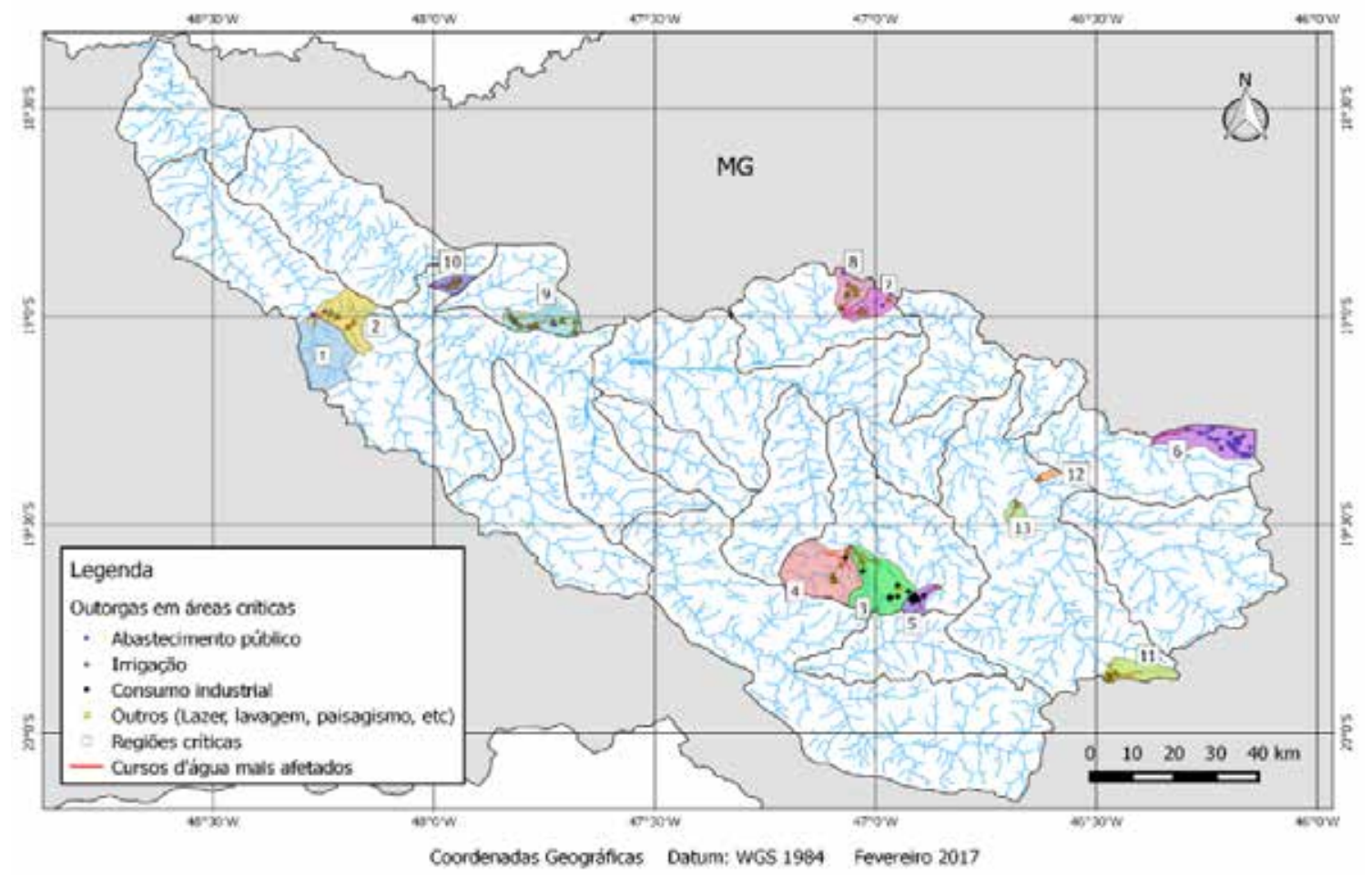


Figura 9 - Déficit para as demandas com períodos superiores a $5 \%$ dos meses (ordenadas, em $\mathrm{hm}^{3}$ )

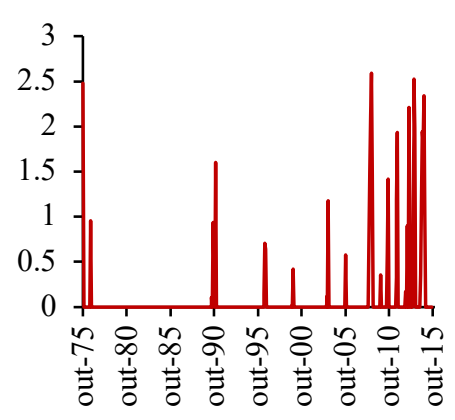

(a) Região 3 - cons. industrial

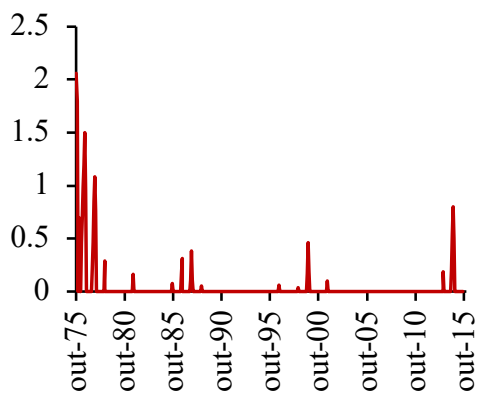

(d) Região 9 - irrigação

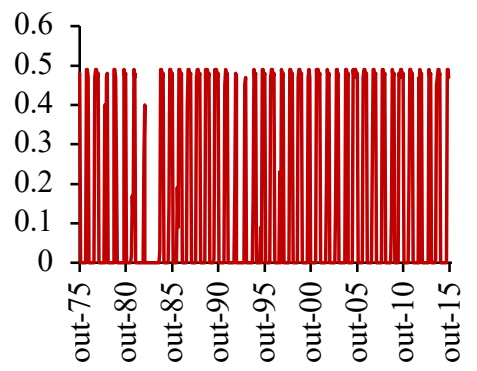

(g) Região 11 - irrigação

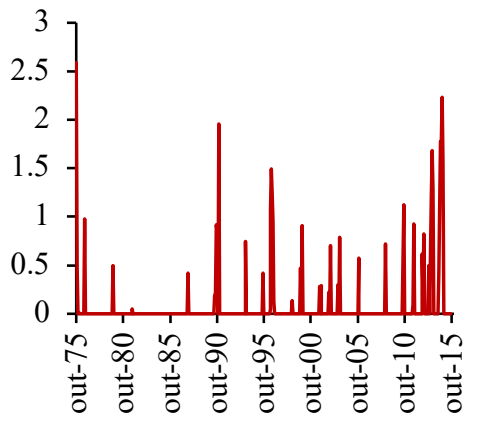

(b) Região 4 - cons. industrial

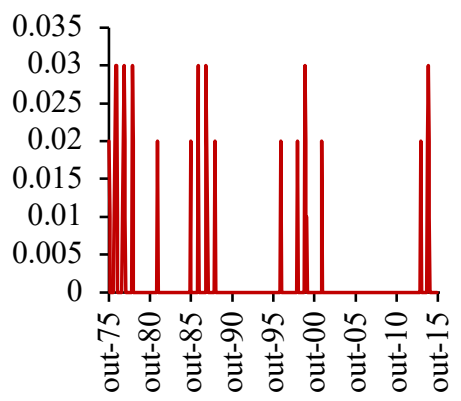

(e) Região $9-$ outros $^{1}$

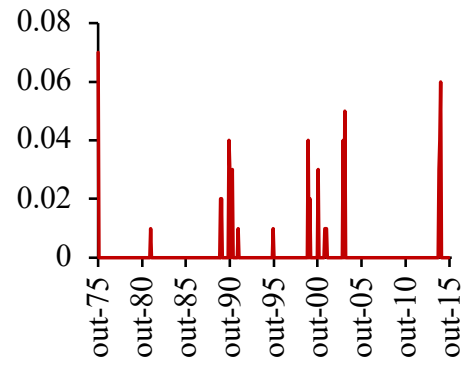

(h) Região 12 - irrigação

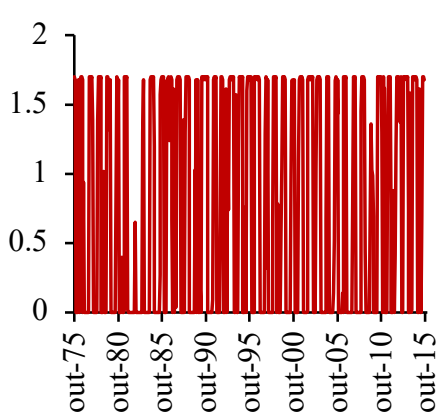

(c) Região 5 - cons. industrial

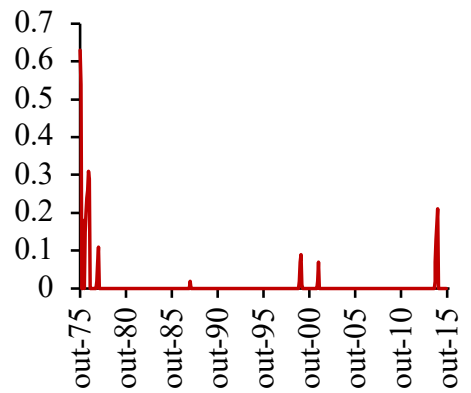

(f) Região 10 - irrigação

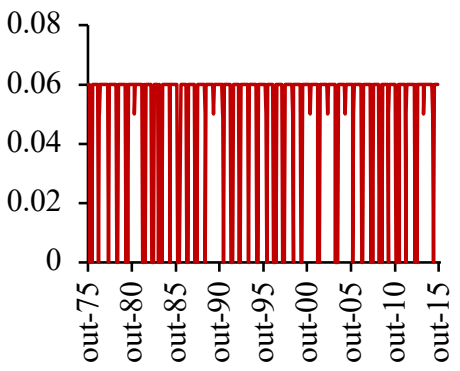

(i) Região 13 - irrigação 


\subsubsection{Reservatórios}

Foram estimados os volumes máximos mensais demandados nos 4 grandes reservatórios em cascata no rio Araguari ( $\mathrm{CH}$ Nova Ponte, $\mathrm{CH}$ Miranda, CHs Capim Branco 1 e 2), sem que se comprometam as exigências mínimas para sua operação. Tais exigências mínimas consideradas foram: respeitar a vazão mínima residual nos cursos a jusante do reservatório $\left(50 \%\right.$ da $\left.Q_{7,10}\right)$; atender às de- mandas atualmente existentes a montante e nos próprios reservatórios, respeitar a cota mínima operacional da hidroelétrica em cada barragem, assim como os volumes mínimos turbinados para geração de energia. A Fig. 10 mostra os volumes acumulados em cada reservatório ao longo do período analisado, para a situação atual (Fig. 10a) e após inseridos os volumes máximos que ainda podem ser demandados (Fig. 10b).

Figura 10 - Distribuição dos volumes armazenados nos 4 grandes reservatórios do rio Araguari: (a) situação atual; (b) após otimização

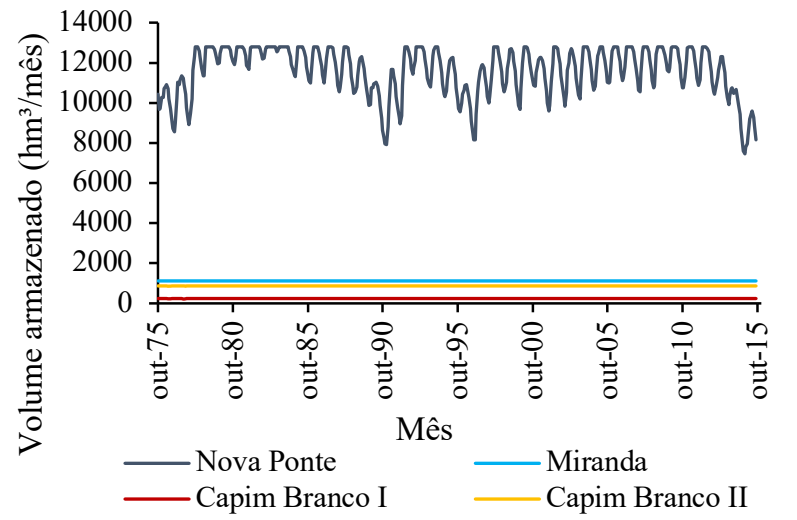

A estimativa do potencial de aproveitamento hídrico ainda existente nesses reservatórios foi realizada inserindo uma nova demanda junto a cada reservatório. Foi estipulado, como parâmetro para os resultados obtidos, que a garantia mensal (Eq. 1) nessas demandas fictícias fosse de pelo me-

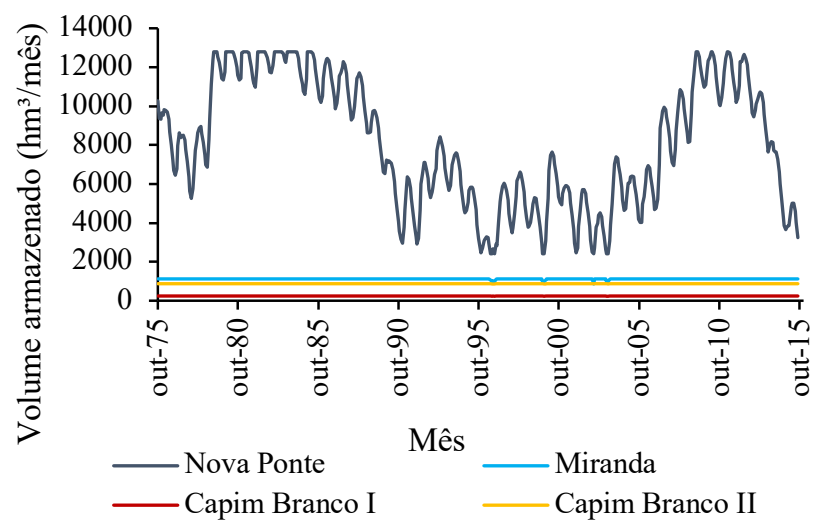

nos $99 \%$. Assim, a Tabela 3 apresenta os volumes máximos mensais, em $\mathrm{hm}^{3}$, que ainda podem ser demandados nas barragens dos reservatórios de Nova Ponte, Miranda, Capim Branco I e Il, sem que se comprometam as exigências mínimas para sua operação (citadas anteriormente).

Tabela 3- Volumes máximos mensais, em $\mathrm{hm}^{3}$, que ainda podem ser outorgados nas barragens dos reservatórios de Nova Ponte, Miranda, Capim Branco I e II

\begin{tabular}{|c|c|c|c|c|c|c|c|c|c|c|c|c|}
\hline & Jan. & Fev. & Mar. & Abr. & Mai. & Jun. & Jul. & Ago. & Set. & Out. & Nov. & Dez. \\
\hline Nova Ponte & 90 & 100 & 100 & 100 & 100 & 100 & 100 & 100 & 85 & 90 & 90 & 85 \\
\hline Miranda & 4 & 6 & 6 & 6 & 6 & 6 & 6 & 6 & 3 & 3 & 3 & 3 \\
\hline CB I & 7,8 & 7,8 & 7,8 & 7,8 & 7,8 & 7,8 & 7,8 & 7,8 & 7,8 & 7,8 & 7,8 & 7,8 \\
\hline CB II & 10 & 10 & 10 & 10 & 10 & 10 & 10 & 10 & 10 & 10 & 10 & 10 \\
\hline
\end{tabular}


Os volumes apresentados na Tabela 3 mostram um grande potencial a ser explorado nesses reservatórios. 0 maior potencial mostrado referese ao reservatório de Nova Ponte, devido à sua capacidade de armazenamento ser pelo menos 10 vezes maior do que a dos demais reservatórios. Nele, os volumes máximos que ainda podem ser captados são de $100 \mathrm{hm}^{3} / \mathrm{mês}$ (fevereiro a agosto), caindo para $90 \mathrm{hm}^{3} / \mathrm{mês}$ (janeiro, outubro e novembro), e atingindo um mínimo de $85 \mathrm{hm} 3 /$ mês (setembro e dezembro). A Tabela 3 também mostra que, para o reservatório de Miranda, a variação dos volumes estimados segue a mesma distribuição, com os maiores valores nos meses de fevereiro a agosto, iguais a $6 \mathrm{hm}^{3} /$ mês, e valores menores para o restante dos meses, sendo de setembro a dezembro iguais a 3 $\mathrm{hm}^{3} / \mathrm{mês}$, e em janeiro igual a $4 \mathrm{hm}^{3} / \mathrm{mês}$. Essa semelhança na distribuição de valores pode estar relacionada ao fato de a $\mathrm{CH}$ de Miranda estar a jusante do reservatório de Nova Ponte e, assim, sofrer os maiores efeitos das variações de seus volumes. Os demais reservatórios (Capim Branco I e II) não apresentam essa variação nos volumes máximos que ainda podem ser captados, provavelmente pelo fato de estarem mais a jusante na sequência em cascata dos reservatórios. $\mathrm{Ne}$ les, os valores encontrados foram constantes ao longo do ano, sendo iguais a $7,8 \mathrm{hm}^{3} / \mathrm{mês}$ para o reservatório de Capim Branco I e iguais a $10 \mathrm{hm}^{3} /$ mês para o reservatório de Capim Branco II.

\section{CONCLUSÕES}

De uma forma geral, os resultados referentes às análises de critérios sazonais visando à otimização do aproveitamento hídrico mostraram que a mudança é viável no período chuvoso; essa substituição representaria um aumento no potencial dos volumes outorgáveis em grande parte da bacia. Para os demais meses, sua aplicação teria como principal resultado a real garantia da vazão residual. Nos trechos onde a vazão atualmente captada ultrapassa o máximo permitido, tanto nos meses secos como nos chuvosos, uma revisão das demandas deferidas deve ser feita, além de uma identificação mais detalhada desses trechos.

A utilização de percentuais mais permissivos da $\mathrm{Q}_{7,10}$ como critério de outorga, frente ao atual, $50 \%$ da $\mathrm{Q}_{7,10}$, teve impactos no aumento do volume outorgável e na solução de conflitos pelo uso da água, como esperado. Entretanto, o principal resultado refere-se à quantificação das regiões da bacia do rio Araguari com demandas outorgadas acima do máximo permitido (geralmente regiões de cabeceira), onde, mesmo após considerar 100\% da Q7,10, tais situações persistem.

No que se refere à segunda análise, apenas em $6 \%$ da área superficial da bacia do rio Araguari a vazão mínima residual de $50 \%$ da $\mathrm{Q}_{7,10}$ não pode ser garantida durante todo o período simulado. Contudo, atenção especial quanto à limitação de outorga deve ser dada nessas áreas. A análise de disponibilidade hídrica nos quatro reservatórios em cascata no rio Araguari mostrou uma situação confortável, com disponibilidade suficiente para outorgas com vazões suficientes para abastecer cidades do porte de Uberlândia (aproximadamente 590.000 habitantes).

De uma forma geral, a situação atual na bacia do rio Araguari é confortável no que diz respeito aos volumes captados, com grande potencial para aumentar seu aproveitamento hídrico. Entretanto, em regiões de cabeceira, estudos mais aprofundados são necessários quanto ao critério de outorga atual e aos volumes captados nessas regiões.

\section{CONTRIBUIÇÃO DOS AUTORES}

Todos os autores contribuíram de forma igualitária. 


\section{REFERÊNCIAS}

AGÊNCIA NACIONAL DE ÁGUAS - ANA. Encarte Especial sobre a Crise Hídrica. Informe 2014. Conjuntura dos Recursos Hídricos no Brasil: Brasília, 2015.

ÁLVAREZ, J. A.; HERNÁNDEZ, J. J. G.; SEGURA, J. M. Un modelo de optimización para el sistema de recursos hidráulicos superficiales Jucar-Turia. Revista de Obras Públicas, v. 133, n. 3244, p. 123132, 1986.

ANDREU, J.; CAPILLA, J:; SANCHIS, E. AQUATOOL, a generalized decision-support system for water-resources planning and operational management. Journal of Hydrology, n. 177, p. 269-291, 1996.

AQUATOOL. Manual de Usuario Versión 1.0. 2015. Disponível em: <www.upv.es/aquatool/>. Acesso em: 20 março 2016.

ATLAS DIGITAL DAS ÁGUAS DE MINAS. 2016. Disponível em: <www.atlasdasaguas.ufv.br>. Acesso em: 16 set. 2016.

BARBOSA, S. E. da S.; BARBOSA JÚNIOR, A. R.; SILVA, G. Q.; CAMPOS, E. N. B.; RODRIGUES, V. C. Geração de modelos de regionalização de vazões máximas, médias de longo período e mínimas de sete dias para a bacia do rio do Carmo, Minas Gerais. Engenharia Sanitária e Ambiental, v. 10, n. 01, p. 64-71, 2005.

BRASIL. Lei $\mathbf{n}^{\circ}$ 9.433, de 08 de janeiro de 1997. Disponível: <www.planalto.gov.br/ccivil_03/leis/L9433.htm>. Acesso em: 30 ago. 2016.

BOF, L. H. N. Análise de critérios de outorga de direito de uso de recursos hídricos. 2010. Dissertação (Mestrado em Engenharia Agrícola) - Universidade Federal de Viçosa, Viçosa, MG, 2010.

CHÁVEZ-JIMÉNEZA, A.; GONZÁLEZ-ZEAS, D. El impacto de los caudales medioambientales en la satisfacción de la demanda de agua bajo escenarios de cambio climático. Revista Iberoamericana del Agua, v. 2, p 3-13, 2015.

COMITÊ DA BACIA HIDROGRÁFICA DO RIO ARAGUARI - CBH Araguari. A Bacia do Rio Araguari. 2016. Disponível em <www.cbharaguari.org.br>. Acesso em: 13 abril 2016.

CORDEIRO, R. S.; MARQQUES, F. A. Sistematização da sazonalidade das vazões características para flexibilização da outorga de direito de uso dos recursos hídricos. In: Seminário de Iniciação Cientifica UFT. Anais... 11 a 14 de Dezembro de 2012, Palmas - Tocantins, Brasil.

COSTA, E. S. Estudo de otimização do aproveitamento hídrico superficial no alto curso do rio Uberaba, UPGRH-GD8. 2015. Dissertação (Mestrado em Engenharia Civil) - Universidade Federal de Uberlândia, Uberlândia, MG, 2015.

DEPARTAMENTO DE ÁGUAS E ENERGIA ELÉTRICA - DAEE. 2016. Disponível em: <www.daee.sp.gov.br/>. Acesso em: 10 jan. 2016.

EUCLYDES, H. P.; FERREIRA, P. A.; FARIA FILHO, R. F. Critério de outorga sazonal para a agricultura irrigada no estado de Minas Gerais - Estudo de Caso. Revista Item - Irrigação e Tecnologia Moderna, Brasília, n. 71/72, p. 42-50, 2006.
EUCLYDES, H. P.; SOUZA, E.F.; FERREIRA, P.A. RH 3.0 - Regionalização hidrológica. (Manual do programa). Viçosa, MG: UFV, DEA; Brasília, DF: MMA; Belo Horizonte, MG: RURALMINAS, 1999. 149 p.

FERREIRA, A. M. Capacidade de autodepuração nos cursos médio e baixo do rio Uberaba, UPGRH-GD8. 2014. Dissertação (Mestrado) - Universidade Federal de Uberlândia, Uberlândia, MG, 2014.

FLUMIGNAN, D. L.; PASTORELLI JÚNIOR, J. H.; MINGOTI, R.; ZOLIN, C. A. Proposta de uso da vazão de referência mensal em substituição à anual no Rio Dourados. Dourados: Embrapa Agropecuária Oeste, 2016.

GIRARDI, R. V.; GOLDENFUM, J. A.; SILVEIRA, A. L. L.; DORNELLES, F. Proposta de um Método Alternativo para Determinação da Precipitação Média Sobre uma Área Utilizando Distâncias Invertidas. Revista Brasileira de Recursos Hídricos, v. 18, n. 1, p. 19-31, 2013.

HEINZ, I.; PULIDO-VELAZQUEZ, M.; LUND, J. R.; ANDREU, J. Hydro-economic Modeling in River Basin Management: Implications and Applications for the European Water Framework Directive. Journal Water Resources Management, vol. 21, p. 1103- 1125, 2007.

HIDROTEC. 2016. Disponível em: <www.hidrotec.ufv.br/>. Acesso em: 17 set. 2016.

HYDROLOGIC ENGINEERING CENTER - HEC. 2016. Disponível em: <www.hec.usace.army.mil>. Acesso em: 25 jun. 2016.

INSTITUTO NACIONAL DE METEOROLOGIA - INMET. 2016. Disponível em: <www.inmet.gov.br/portal/>. Acesso em: 4 maio. 2016.

JARDIM, C. H. A "Crise Hídrica" no Sudeste do Brasil: Aspectos Climáticos e Repercussões Ambientais. Tamoios, v. 11, n. 2, p. 67-83, 2015.

LANDIM, P. M. B. Introdução aos métodos de estimação espacial para confecção de m-pas. UNESP/Campus de Rio Claro/Departamento de Geologia Aplicada - IGCE - Laboratório de Geomatemática - Texto Didático 02, 2000.

LONGHI, E. H.; FORMIGA, K. T. M. Metodologias para determinar vazão ecológica em rios. Revista Brasileira de Ciências Ambientais, n. 20, p. 33-48, 2011.

MAS, A.G.C. Evaluación del recurso hídrico en la cuenca del río Turia (España) median-te la aplicación de modelos semiagregados de Precipitación-Escorrentía. Proyecto Final de Carrera. Ingeniería de Caminos, Canales y Puertos. Universidad Politécnica de Valencia, Valen-cia, 147 p., 2013.

MEDEIROS, P. C.; SOUZA, F. A. S.; RIBEIRO, M. M. R. Aspectos conceituais sobre o regime hidrológico para a definição do hidrograma ambiental. Ambi-Agua, v. 6, n. 1, p. 131-147, 2011.

OLIVEIRA, J. R. de; PRUSKI, F. F.; NUNES, A. A. Otimização do aproveitamento da dispo-nibilidade de Águas Superficiais na Bacia do Ribeirão entre Ribeiros. Revista Brasileira de Recursos Hídricos, v. 18, n. 4, 157-172, 2013. 
PAREDES-ARQUIOLA, J.; SOLERA, A.; MARTINEZ-CAPEL, F.; MOMBLANCH, A.; ANDREU, J. Integrating water management, habitat modelling and water quality at the basin scale and environmental flow assessment: case study of the Tormes River, Spain. Hydrological Sciences Journal, v. 59, n. 3-4, p. 878-889, 2014 a.

PAREDES-ARQUUIOLA J.; SOLERA, A.; ÁlVAREZ, J. A.; ELVIRA, N. L. Herramienta EvalHid para la evaluación de recursos hídricos. Versión 1.1. Valencia: Universidad Politécnica de Valencia, 2014b. 52 p.

PAREDES-ARQUIOLA, J.; ÁLVAREZ, J. A.; SOLERA, A. 2009. AQUATOOL +: Entorno de desarrollo de sistemas de ayuda a la decisión en materia de planificación de la gestión de cuencas hidrográficas incluyendo utilización conjunta y criterios de calidad de aguas. Manual del usuario. Versión 1.0. Valencia: Universidad Politécnica de Valencia, 2015. 81 p.

PELLICER-MARTÍNEZ, F.; MARTíNEZ-PAZ, F. J. M. Grey water footprint assessment at the river basin level: Accounting method and case study in the Segura River Basin, Spain. Ecological Indicators, v. 60 , p. 1173-1183, 2016.

PINTO, V. G; RIBEIRO, C. B. M; SILVA, D. D. Vazão ecológica e o arcabouço legal brasileiro. Revista Brasileira de Geografia Física, v. 9 , n. 1, p. 091-109, 2016.

PRUSKI, F. F.; BOF, L. H. N.; DA SILVA, L. M. C.; DA SILVA, J. M. A.; REGO, F. S.; JUSTINO, F. B. Impact of the substitution of reference annual streamflow by monthly stream-flow on the potential use of water resources. Engenharia Agrícola, v. 34, n. 3, p. 496-509, 2014.

SALLA, M. R.; PAREDES-ARQUUIOLA, J.; SOLERA, A.; ALVARÉZ, J. A.; PEREIRA, C. E.; ALAMY FILHO, J. E.; OLIVEIRA, A. L de. Variabilidade em produção de energia hidrelétrica na bacia hidrográfica do rio Araguari, Minas Gerais. In: XX Simpósio Brasileiro de Recursos Hídricos. Anais... 17 a 22 de Novembro de 2013, Bento Gonçalves - Rio Grande do Sul, Brasil.

SALLA, M. R.; PAREDES-ARQUUIOLA J.; SOLERA, A.; ÁlVAREZ, J. A.; PEREIRA, C. E.; ALAMY FILHO, J. E.; OLIVEIRA, A. L. Integrated modeling of water quantity and quality in the Araguari River basin, Brazil. Latin American Journal of Aquatic Research, Val-paraíso, v. 42, n. 1, p. 224-244, 2014 a.

SALLA, M. R.; PAREDES-ARQUUIOLA J.; SOLERA, A.; ALVARÉZ, J. A.; PEREIRA, C. E.; ALAMY FILHO, J. E.; OLIVEIRA, A. L. de. Sistema de Suporte à Decisão em Recursos Hídricos na Bacia Hidrográfica do Rio Uberabinha, Minas Gerais. Revista Brasileira de Re-cursos Hídricos, v. 19, n. 1, p. 189-204, 2014b.

SALLA, M. R.; PAREDES-ARQQUIOLA J.; ELVIRA, N. L; ALAMY FILHO, J. E.; COSTA, E. S. Aplicação da ferramenta EvalHid para calibração de parâmetros e simulação de vazões no alto curso do rio Aragua- ri, Minas Gerais. Revista Brasileira de Recursos Hídricos, Porto Alegre, v. 19, n.1.p. 189-204, 2015.

SECRETARIA DE ESTADO DE MEIO AMBIENTE E DESENVOLVIMENTO SUSTENTÁVEL - SEMAD. 2016. Disponível em: <www.semad. mg.gov.br>. Acesso em: 14 fev. 2016.

SILVA, D. D.; MARQUUES, F. A.; LEMOS, A. F. Flexibilidade das vazões mínimas de refe-rência com a adoção do período trimestral. Engenharia na Agricultura, Viçosa, v. 19, n. 3, p. 244-254, 2011.

SILVA, F. C. Análise Integrada de Usos de Água Superficial e Subterrânea em Macro-escala numa Bacia Hidrográfica: o caso do Alto Rio Paranaíba. 2007. Dissertação (Mestrado em Recursos Hídricos e Saneamento) - Universidade Federal do Rio Grande do Sul, Porto Alegre, RS, 2007.

SILVA, V. S. V. Estimativa de precipitação pontual em diferentes escalas para uso em modelo concentrado chuva-vazão. 2011. Dissertação (Mestrado) - Universidade Federal do Rio Grande do Sul, Porto Alegre, RS, 2011.

SIMÕES, J.; OLIVEIRA, R. P. Modelos de gestão de bacias hidrográficas: aplicação do IRAS-2010 e do AQUATOOL ao aproveitamento hidroagrícola do Vale do Sorraia. Recursos Hídricos, v. 35, n. 2, p. 29-39, 2014.

SOARES, A. Geoestatística para as ciências da terra e do ambiente. Lisboa: Instituto Supe-rior Técnico, 2000.

SOPHOCLEOUS, M. Interaction setween groundwater and surface water: the state of the Science. Hydrogeology Journal, v. 10, p. $52-67,2002$

SOSINSKI, L.W. A gestão dos usos múltiplos da água. 2010. Artigo em Hypertexto. Disponível em: <www.infobibos.com/Artigos/2010_1/agua/index.htm>. Acesso em: 17 nov. 2016.

SOUZA, S. M. T. Deflúvios superficiais no estado de Minas Gerais. Belo Horizonte: Hidrossistemas, 264p., 1998.

TOMAZ, P. Critério Unificado para Manejo das Águas Pluviais em Áreas Urbanas. Capítulo 15 -Vazão base e vazão mínima ecológica. 2012. Disponível em: www.pliniotomaz.com.br/. Acesso em: 14 fev. 2016.

TUCCI, C. E. M. Modelos Hidrológicos. 2 ed. Porto Alegre: Editora da UFRGS, 2005.

VESTENA, L. R.; OLIVEIRA, E. D.; CUNHA, M. C.; THOMAZ, E. L. Vazão ecológica e disponibilidade hídrica na bacia das Pedras, Guarapuava-PR. Ambi-Agua, v. 7, n. 3, p. 212-227, 2012.

VON SPERLING, M. Estudos e modelagem da qualidade da água de rios. Belo Horizonte: Departamento de Engenharia Sanitária e Ambiental, UFMG, 2007. 